\title{
Understanding Complexometric Titrations of Metal Cations with Aminopolycarboxylic Acids (EDTA and Analogs) within the frame of the Notion of Reactions between Groups of Chemical Species
}

\author{
Maria Michela SALVATORE*, Francesco SALVATORE \\ Dipartimento di Scienze Chimiche, Università degli Studi di Napoli “Federico II”, Via Cintia, 21 - 80126 Napoli, Italy \\ *Corresponding author: frsalvat@unina.it
}

Received December 15, 2014; Revised February 02, 2015; Accepted February 09, 2015

\begin{abstract}
In spite of the apparent technical simplicity with which visual complexometric titrations of metal cations with aminopolycarboxylic acids titrants are performed, a complex chemistry takes place in the titrated solution during the titration, due to the chemical environment and to the insuppressible chemical properties of metal cations, aminopolycarboxylic acids and metallochromic indicators. This chemical complexity makes rigorous exposition and evaluations of complexometric titrations arduous. Nonetheless, by the introduction of the notions of groups of chemical species and reactions between groups of chemical species (with the connected concept of conditional formation constant), a frame is created within which complexometric titrations with aminopolycarboxylic acids can be collocated and which allows a reasonably simple presentation and evaluation of the analytically relevant aspects of this type of titrations. In a sense, the well known concept of conditional complex formation constant is updated in a way that facilitates understanding and use.
\end{abstract}

Keywords: aminopolycarboxylic acids, complexometric titrations, conditional formation constant, EDTA, magnesium, Eriochrome Black T, water hardness

Cite This Article: Maria Michela SALVATORE, and Francesco SALVATORE, "Understanding Complexometric Titrations of Metal Cations with Aminopolycarboxylic Acids (EDTA and Analogs) within the frame of the Notion of Reactions between Groups of Chemical Species.” World Journal of Chemical Education, vol. 3, no. 1 (2015): 5-21. doi: 10.12691/wjce-3-1-2.

\section{Introduction}

Aminopolycarboxylic acids are a class of multidentate chelating ligands which are very effective in complexing metal cations through oxygen and nitrogen donor atoms.

Because of this capability, they are employed in a variety of ways in chemistry and in other fields.

A large number of aminopolycarboxylic acids have been synthesized and examined for their properties in complexing metal cations, but only a small number of them are in common use [1].

The most popular of all the aminopolycarboxylic acids is ethylendiaminetetraacetic acid $\left(\mathrm{H}_{4} \mathrm{EDTA}\right)$ which corresponds to the structure [2,3]:<smiles>O=C(O)CN(CCN(CC(=O)O)CC(=O)O)CC(=O)O</smiles>

Diethylenetriaminepentaacetic acid $\left(\mathrm{H}_{5} \mathrm{DPA}\right)$ and diaminocyclohexanetetraacetic acid $\left(\mathrm{H}_{4} \mathrm{DCTA}\right)$, which correspond to the following structures, are also very common and in many aspects equivalent to EDTA:

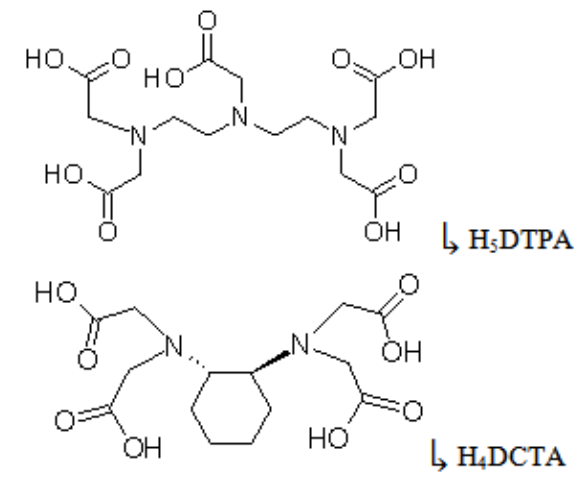

Probably, the most popular application of aminopolycarboxylic acids in chemistry is their use as titrants in complexometric titrations for the determination of a variety of metal cations [4].

Visual direct complexometric titrations are very rapid and convenient and are performed in a way that is 
technically very similar to other types of titrations (e.g., visual Acid-Base titrations) [2,3].

In a visual direct complexometric titration a volume $V_{0}^{l}$ ( $l=$ litre) of a solution (buffered to a suitable $\mathrm{pH}$ by addition of a $\mathrm{pH}$ buffer) containing a concentration $C_{0}^{\mathrm{M}}$ ( $\mathrm{M}=$ Molar) of the target metal cation $\mathrm{Me}^{\mathrm{z+}}$ is coloured by adding a small amount of a metallochromic indicator and then titrated by adding, from a burette, accurately measured volumes, $V_{\mathrm{t}}^{\mathrm{l}}$, of the titrating $C_{\mathrm{t}}^{\mathrm{M}}$ aminopolycarboxylic acid standard solution. The titration is continued until a sudden change in colour of the solution is observed, at which point the total volume, $V_{\text {arr }}^{l}$, of the aminopolycarboxylic acid standard solution consumed, is read on the burette and used to evaluate the amount $\left(C_{0}^{\mathrm{M}} \cdot V_{0}^{l}\right)$ or concentration $\left(C_{0}^{\mathrm{M}}\right)$ of the metal cation in the titrated solution.

For a direct complexometric titration, as for any titration, an equivalent volume exists, $V_{\mathrm{eq}}^{l}$, which is, by definition, the point of the titration when the number of moles of the titrant aminopolycarboxylic acid added is equal to the number of moles of the target metal cation.

Evaluations are performed by identifying $V_{\text {arr }}^{l}$ determined from the titration with $V_{\mathrm{eq}}^{l}$ on the basis of relation (1), which holds at the equivalence point of the direct titration of a metal with an aminopolycarboxylic acid ligand:

$$
C_{\mathrm{t}}^{\mathrm{M}} \cdot V_{\mathrm{eq}}^{l}=C_{0}^{\mathrm{M}} \cdot V_{0}^{l}
$$

Because the left side member of equation (1) can be calculated from the titration data, either the number of moles of the target metal ( $C_{0}^{\mathrm{M}} \cdot V_{0}^{l}$ ) or its concentration (if a measured volume $V_{0}^{l}$ of the metal cation solution has been delivered to the titration vessel) can be readily obtained.

Please note that in each point of the titration, specified by the value of the variable $V_{\mathrm{t}}^{l}$, a defined analytical concentration, $C_{\mathrm{APCA}}^{\mathrm{M}}$, of the aminopolycarboxylic acid exists in the titrated solution. This concentration can be calculated from relation (2):

$$
C_{\mathrm{APCA}}^{\mathrm{M}}=\frac{C_{\mathrm{t}}^{\mathrm{M}} \cdot V_{\mathrm{t}}^{l}}{V_{\mathrm{t}}^{l}+V_{0}^{l}}
$$

Analogously, in each point of the titration it exists a concentration of the target metal cation, $C_{\mathrm{Me}}^{\mathrm{M}}$, which can be calculated from relation (3):

$$
C_{\mathrm{Me}}^{\mathrm{M}}=\frac{C_{0}^{\mathrm{M}} \cdot V_{0}^{l}}{V_{\mathrm{t}}^{l}+V_{0}^{l}}
$$

From equations (2) and (3) we see that, while the variable $V_{\mathrm{t}}^{l}$ is increased during the titration, the analytical concentration of the aminopolycarboxylic acid (which is initially zero) increases, while the analytical concentration of the metal cation decreases. Since $C_{\mathrm{APCA}}^{\mathrm{M}}$ increases and
$C_{\mathrm{Me}}^{\mathrm{M}}$ decreases during the titration, there will be a point when they become equal and relation (4) is verified:

$$
C_{\mathrm{APCA}}^{\mathrm{M}}=C_{\mathrm{Me}}^{\mathrm{M}}
$$

This point is, by definition, the equivalence point. The aim of any analytical complexometric titration is to identify the value of $V_{t}^{l}$ for which relation (4) holds in the titrated solution.

Evidently, condition (1) is derived by combining relations (2), (3) and (4) for $V_{\mathrm{t}}^{l}=V_{\mathrm{eq}}^{l}$.

The above definition of the equivalence point is justified from the fact that the fundamental reaction which takes place between the target metal cation, $\mathrm{Me}^{\mathrm{z+}}$, and an amino polycarboxylate anion, APCA $^{n-}$ has a very simple 1 : 1 stoichiometry shown in (5):

$$
\mathrm{Me}^{\mathrm{z}+}+\mathrm{APCA}^{n-} \rightleftharpoons \operatorname{MeAPCA}^{(n-z)-}
$$

The equilibrium constant of reaction (5) is generally denoted by $\beta_{1}$ :

$$
\beta_{1}=\frac{\left[\operatorname{MeAPCA}^{(n-z)-}\right]}{\left[\operatorname{Me}^{\mathrm{z}+}\right]\left[\mathrm{APCA}^{n-}\right]}
$$

For instance, if $\mathrm{Me}^{\mathrm{z}+}=\mathrm{Zn}^{2+}$ and $\mathrm{APCA}^{n-}=\mathrm{EDTA}^{4-}$ we have reaction (7), which would take place during the titration of a solution of $\mathrm{Zn}^{2+}$ with standard EDTA solution:

$$
\begin{aligned}
& \mathrm{Zn}^{2+}+\mathrm{EDTA}^{4-} \rightleftharpoons \mathrm{ZnEDTA}^{2-} \\
& \beta_{1}=\frac{\left[\mathrm{ZnEDTA}^{2-}\right]}{\left[\mathrm{Zn}^{2+}\right]\left[\mathrm{EDTA}^{4-}\right]}=10^{16.5}
\end{aligned}
$$

Please note that the simple stoichiometry of complexes and the large values of the corresponding formation constants are at the basis of the usefulness of this class of ligands $[4,5]$.

The metallochromic indicator, $\mathrm{In}^{n-}$, which is responsible for the colour change of the titrated solution when the titration is stopped, is itself a chelating agent which reacts with the target metal cation according to the simple reaction (9):

$$
\begin{gathered}
\mathrm{Me}^{\mathrm{z+}}+\mathrm{In}^{n-} \rightleftharpoons \operatorname{MeIn}^{(n-\mathrm{z})-} \\
\beta_{1}^{\mathrm{In}}=\frac{\left[\operatorname{MeIn}^{(n-\mathrm{z})-}\right]}{\left[\mathrm{Me}^{\mathrm{z}+}\right]\left[\mathrm{In}^{n-}\right]}
\end{gathered}
$$

However, for the present purposes, it is useful to note that $\mathrm{In}^{n-}$ is a base which may exist as several protonated species, $\mathrm{H}_{h} \mathrm{In}{ }^{(n-h)-}$, which differ in the degree of protonation, and that reaction (9) can be rewritten in the form:

$$
\mathrm{Me}^{\mathrm{z+}}+\mathrm{H}_{h} \mathrm{In}^{(n-h)-} \rightleftharpoons \operatorname{MeIn}^{(n-z)-}+h \mathrm{H}^{+}
$$

The outstanding property of a metallochromic indicator is the fact that the free indicator, $\mathrm{H}_{h} \mathrm{In}^{(n-h)-}$, has a colour which differs from the colour of the complex $\operatorname{MeIn}^{(n-z)-}$. 
At the beginning of the complexometric titration, because of the excess of $\mathrm{Me}^{\mathrm{z+}}$ in the titrated solution, we see the colour of the complex MeIn ${ }^{(n-z)-}$. As the titration advances, $\mathrm{Me}^{\mathrm{z+}}$ progressively disappears from the solution because of reaction (5), until a point is reached when the MeIn ${ }^{(n-z)-}$ complex is decomposed to the free indicator. At this point, the colour of the solution changes from that of MeIn ${ }^{(n-z)-}$ to that of $\mathrm{H}_{h} \mathrm{In}^{(n-h)-}$.

As it happens, the colour of the $\mathrm{H}_{h} \mathrm{In}^{(n-h)-}$ species depends on the number of bonded protons.

As a consequence, the colour observed when the MeIn $(n-z)-$ complex is decomposed depends on the prevailing $\mathrm{H}_{h} \mathrm{In}^{(n-h)-}$ species formed; which, in turn, depends on the $\mathrm{pH}$ of the titrated solution. In order to fix the colour of the solution after the equivalence point the $\mathrm{pH}$ of the titrated solution is buffered to a suitable value by adding a $\mathrm{pH}$ buffer [2-6]. This is unavoidable because it often happens that one or more of the $\mathrm{H}_{h} \mathrm{In}^{(n-h)-}$ species have the same colour as the complex MeIn ${ }^{(n-z)-}$. Obviously, if a $\mathrm{H}_{h} \mathrm{In}^{(n-h)-}$ species, which has the same colour as MeIn ${ }^{(n-z)-}$, is formed, no change in colour will be observed.

In other words, a metallochromic indicator is such only in a restricted range of $\mathrm{pH}$ in which the prevailing form of the free indicator has a colour which differs from the colour of its complex with the target metal cation.

For instance, one of the most popular metallochromic indicators is Eriochrome Black $\mathrm{T}$ (EBT) which corresponds to the structure:<smiles>O=[N+]([O-])c1ccc2c(/N=N\c3ccc4ccccc4c3O)c(O)cc(S(=O)(=O)O)c2c1</smiles>

$\hookrightarrow$ Eriochrome Black T (sodium salt)

The full protonated species of EBT is $\mathrm{H}_{2} \mathrm{EBT}^{-}$which has a red colour and is the prevailing species up to $\mathrm{pH} \approx$ 6.5. The dissociation of a proton from $\mathrm{H}_{2} \mathrm{EBT}^{-}$produces $\mathrm{HEBT}^{2-}$ which has a blue colour and is the prevailing $\mathrm{H}_{h} \mathrm{EBT}^{(3-h)-}$ specie in the $\mathrm{pH}$ range $\sim 7<\mathrm{pH}<\sim 11$. The full deprotonated species $\mathrm{EBT}^{3-}$ has an orange colour and prevails at the highest $\mathrm{pH}$. Now, since the $\operatorname{MeEBT}^{(3-z)-}$ complexes have a red colour (regardless of the nature of the metal), it is quite evident that Eriochrome Black $\mathrm{T}$ is not a metallochromic indicator at $\mathrm{pH}$ lower than about 7 .

From the above, it may also be deduced that a metallochromic indicator is in primis an Acid-Base indicator, so much so that a change in colour may be observed in the titrated solution because of an unintended $\mathrm{pH}$ change following the addition of the titrant, even in a point which is far from the equivalence point of the complexometric titration. This event is also prevented by $\mathrm{pH}$ buffering the titrated solution.

\section{The Chemical Complexity of Complexometric Titrations}

In spite of the apparent operational simplicity of a direct complexometric titration, a very complex chemistry unfolds in the titrated solution as the titration progresses.
This chemistry is not of direct interest to the experimentalist, but must be considered in detail in order to state the conditions which must be met if accurate results must be derived from a complexometric titration.

To give an example, consider the titration of a $\mathrm{Zn}^{2+}$ solution, $\mathrm{pH}$ buffered with an $\mathrm{NH}_{3} / \mathrm{NH}_{4}{ }^{+}$buffer, with a standard solution of EDTA in presence of EBT as indicator.

In abstract, all the reactions listed in Table 1 take place in the titrated solution as the titration progresses.

Table 1. List of reactions taking place in an aqueous ammoniacal solution containing Zinc ${ }^{2+}+$ EDTA + Eriochrome Black T [7]

\begin{tabular}{|c|c|c|}
\hline 1 & $\mathrm{Zn}^{2+}+\mathrm{EDTA}^{4-} \leftrightharpoons \mathrm{ZnEDTA}^{2-}$ & $\log \beta=16.440$ \\
\hline 2 & $\mathrm{Zn}^{2^{+}}+\mathrm{EBT}^{3^{-}} \leftrightharpoons \mathrm{ZnEBT}^{-}$ & $\log \beta=12.61$ \\
\hline 3 & $\mathrm{Zn}^{2+}+\mathrm{OH}^{-} \leftrightharpoons \mathrm{ZnO}$ & $\log \beta=5.003$ \\
\hline 4 & $\mathrm{Zn}^{2^{+}+2 \mathrm{OH}^{-} \leftrightharpoons \mathrm{Zn}(\mathrm{OH})_{2}}$ & $\log \beta=11.106$ \\
\hline 5 & $\mathrm{Zn}^{2+}+3 \mathrm{OH}^{-} \leftrightharpoons \mathrm{Zn}(\mathrm{OH})_{3}^{-}$ & $\log \beta 13.609$ \\
\hline 6 & $\mathrm{Zn}^{2+}+4 \mathrm{OH}^{-} \leftrightharpoons \mathrm{Zn}(\mathrm{OH})_{4}{ }^{2-}$ & $\log \beta=14.812$ \\
\hline 7 & $\mathrm{EDTA}^{4-}+\mathrm{H}^{+} \leftrightharpoons \mathrm{HEDTA}^{3-}$ & $\log \beta=10.170$ \\
\hline 8 & $\mathrm{EDTA}^{4-}+2 \mathrm{H}^{+} \leftrightharpoons \mathrm{H}_{2} \mathrm{EDTA}^{2-}$ & $\log \beta=16.280$ \\
\hline 9 & $\mathrm{EDTA}^{4-}+3 \mathrm{H}^{+} \leftrightharpoons \mathrm{H}_{3} \mathrm{EDTA}^{-}$ & $\log \beta=18.960$ \\
\hline 10 & $\mathrm{EDTA}^{4-}+4 \mathrm{H}^{+} \leftrightharpoons \mathrm{H}_{4} \mathrm{EDTA}$ & $\log \beta=20.960$ \\
\hline 11 & $\mathrm{EBT}^{3^{-}}+\mathrm{H}^{+} \leftrightharpoons \mathrm{HEBT}^{2-}$ & $\log \beta=11.390$ \\
\hline 12 & $\mathrm{EBT}^{3^{-}}+2 \mathrm{H}^{+} \leftrightharpoons \mathrm{H}_{2} \mathrm{EBT}^{-}$ & $\log \beta=18.290$ \\
\hline 13 & $\mathrm{ZnEDTA}^{2-}+\mathrm{H}^{+} \leftrightharpoons \mathrm{ZnHEDTA}^{2-}$ & $\log \beta=3.00$ \\
\hline 14 & $\mathrm{ZnEDTA}^{2-}+\mathrm{OH}^{-} \leftrightharpoons \mathrm{Zn}(\mathrm{OH}) \mathrm{EDTA}^{3-}$ & $\log \beta=2.10$ \\
\hline 15 & $\mathrm{Zn}^{2^{+}}+\mathrm{NH}_{3} \leftrightharpoons \mathrm{Zn}\left(\mathrm{NH}_{3}\right)^{2^{+}}$ & $\log \beta=2.21$ \\
\hline 16 & $\mathrm{Zn}^{2^{+}}+2 \mathrm{NH}_{3} \leftrightharpoons \mathrm{Zn}\left(\mathrm{NH}_{3}\right)_{2}{ }^{2^{+}}$ & $\log \beta=4.50$ \\
\hline 17 & $\mathrm{Zn}^{2^{+}}+3 \mathrm{NH}_{3} \leftrightharpoons \mathrm{Zn}\left(\mathrm{NH}_{3}\right)_{3}$ & $\log \beta=6.86$ \\
\hline 18 & $\mathrm{Zn}^{2^{+}}+4 \mathrm{NH}_{3} \leftrightharpoons \mathrm{Zn}\left(\mathrm{NH}_{3}\right)_{4}{ }^{2^{+}}$ & $\log \beta=8.89$ \\
\hline 19 & $\mathrm{NH}_{3}+\mathrm{H}^{+} \leftrightharpoons \mathrm{NH}_{4}^{+}$ & $\log \beta=9.290$ \\
\hline 20 & $\mathrm{H}_{2} \mathrm{O} \leftrightharpoons \mathrm{H}^{+}+\mathrm{OH}^{-}$ & $\log K_{\mathrm{w}}=-14.00$ \\
\hline
\end{tabular}

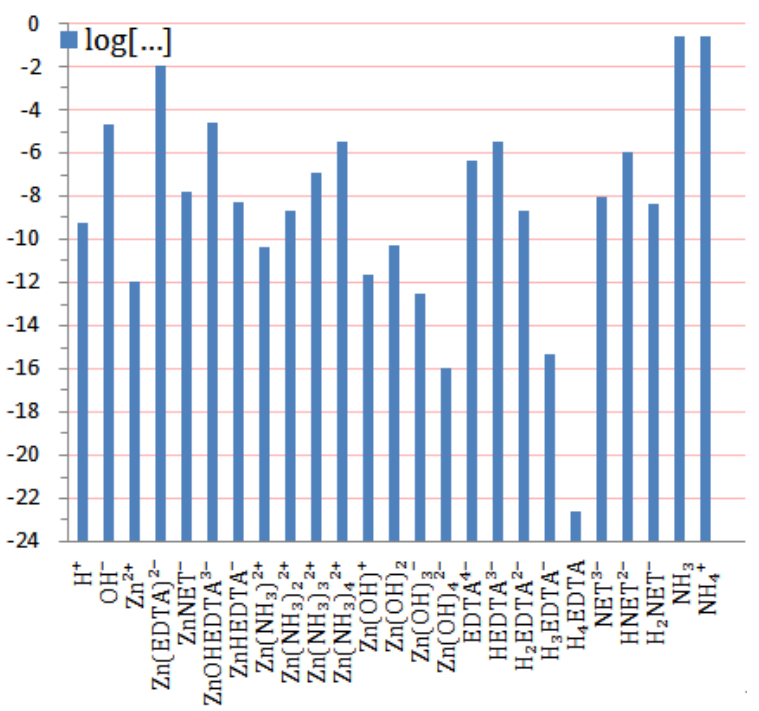

Figure 1. Histogram representing the equilibrium concentrations of species present in a solution $0.01 \mathrm{M} \mathrm{Zn}^{2+}+0.01 \mathrm{M} \mathrm{EDTA}^{4-}+0.25 \mathrm{M}$ $\mathrm{NH}_{3}+0.25 \mathrm{M} \mathrm{NH}_{4}{ }^{+}+10^{-6} \mathrm{M}$ Eriochrome Black T. The log of the equilibrium concentration of a selected species can be read in correspondence of the apex of each bar (the length of the bar increases as the concentration of the corresponding species)

This long list of reactions derives from the fact that a metal cation in water is a Brönsted acid which forms hydroxo complexes (see reactions from 3 to 6 in Table 1) and the amino carboxylate anion and the indicator are bases which can be protonated (see reactions from 7 to 10 and reactions 11 and 12 in Table 1). Furthermore, the presence of the $\mathrm{NH}_{4}^{+} / \mathrm{NH}_{3} \mathrm{pH}$ buffer introduces an auxiliary ligand, i.e., $\mathrm{NH}_{3}$, which competes with the primary ligand, i.e., $\mathrm{EDTA}^{4-}$, for the metal cation (see 
reactions from 15 to 18 in Table 1 ). Finally, according to reaction 13 and 14 in Table 1, the primary complex $\mathrm{ZnEDTA}^{2-}$ may react with $\mathrm{H}^{+}$to form the acid complex $\mathrm{ZnHEDTA}^{-}$; or, with $\mathrm{OH}^{-}$to form a basic complex $\mathrm{Zn}(\mathrm{OH}) \mathrm{EDTA}^{3-}$.

Since, in abstract, any reaction taking place in the titrated solution produces a new species, it follows that a large number of different species are generally present in the titrated solution during the titration.

This point is stressed in Figure 1 for the particular case of a $0.01 \mathrm{M} \mathrm{Zn}^{2+}+0.01 \mathrm{M} \mathrm{EDTA}^{4-}+0.25 \mathrm{M} \mathrm{NH}_{3}+0.25$ $\mathrm{M} \mathrm{NH}_{4}^{+}+10^{-6} \mathrm{M}$ Eriochrome Black T solution.

This state of affairs is replicated with obvious variations which depend on the specific nature of the metal cation, of the titrating aminopolycarboxylic acid, of the auxiliary ligand and of the indicator in any complexometric titration $[4,5,8,9]$.

$$
\begin{aligned}
& \mathrm{Me}^{\mathrm{z}+}+\mathrm{APCA}^{n-} \stackrel{\beta_{1}}{\rightleftharpoons} \mathrm{MeAPCA}^{(n-z)-} \\
& \mathrm{Me}^{\mathrm{z}+}+\operatorname{In}^{n-} \stackrel{\beta_{1}^{\mathrm{In}}}{\rightleftharpoons} \operatorname{MeIn}_{\uparrow}^{(n-z)-} \\
& \text { 今) } \\
& \downarrow \text { Side Reactions }- \text { Side Reactions of } \mathrm{Me}^{\mathrm{z}+} \longrightarrow
\end{aligned}
$$

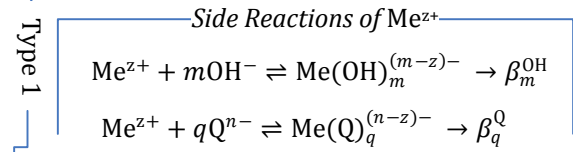

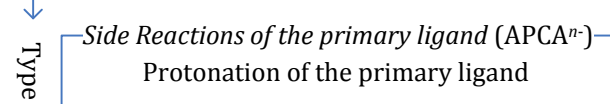

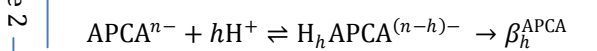

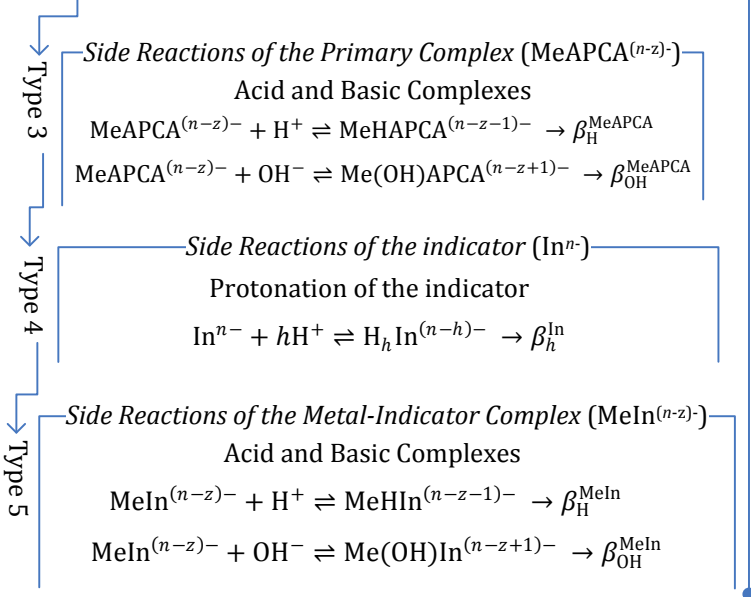

Figure 2. Primary reactions and various types of side reactions typically observed during a complexometric titration. $\mathrm{Me}^{\mathrm{z}+}, \mathrm{APCA}^{n-}, \mathrm{In}^{n-}, \mathrm{Q}^{n_{-}}$ represent, respectively, the target metal cation, the amino polycarboxylate anion, the indicator and the auxiliary ligand introduced as a component of the $\mathrm{pH}$ buffer. See Table 1 for examples of each type of reaction

Figure 2 presents a general scheme of the reactions which typically occur during a complexometric titration.

In Figure 2, the reactions which take place in the titrated solution are classified as primary reactions, which are functional to the titration, and side reactions which are unintended reactions due to insuppressible chemical properties of reactants and products of the primary reactions. Side reactions are classified as hydrolysis reactions and complex formation reactions of the metal cation with the auxiliary ligand (symbolized by $\mathrm{Q}^{n_{-}}$). Then, there are in general side reactions of protonation of the primary ligand $\left(\mathrm{APCA}^{n_{-}}\right)$and of the indicator $\left(\mathrm{In}^{n_{-}}\right)$. Finally, the reactions of the primary complexes, MeAPCA ${ }^{(n-z)}$ and $\mathrm{MeIn}^{(n-z)_{-}}$, to form acid and basic complexes, may occur.

Please note that, in Figure 2, a special symbol for the equilibrium constant of each type of reaction (which will be used in the following) is introduced.

Please refer to Table 1 for specific examples of the general reactions in Figure 2 and for typical values of the corresponding equilibrium constants.

Evidently, there it is a conspicuous number of reactions in the titrated solution that are unnecessary for the titration, but which cannot be suppressed and must, then, be considered because they have an effect on the yield of the primary reactions and can dramatically change the outcome of the titration.

\subsection{Overcoming Side Reactions}

Side reactions which take place during a complexometric titration enormously complicate evaluations and discussions concerning this type of titrations.

By the way of example, suppose that you want to translate the simple condition (4), i.e. $C_{\mathrm{APCA}}^{\mathrm{M}}=C_{\mathrm{Me}}^{\mathrm{M}}$, which defines the equivalence point of the titration, via the equilibrium concentrations, [...], of the species present in the solution.

To this end, one may start by writing the mass balances for the metal and aminopolycarboxylic acid in the solution.

The mass balance of the metal contains a long list of species:

$$
\begin{aligned}
& C_{M e}^{M}=\left[\mathrm{Me}^{\mathrm{Z}+}\right]+\left[\mathrm{MeOH} \cdot{ }^{\cdot}\right]+\left[\mathrm{Me}(\mathrm{OH})_{2}^{\ddot{*}}\right]+
\end{aligned}
$$

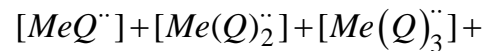

$$
\begin{aligned}
& {\left[\mathrm{MeAPCA}^{*}\right]+[\mathrm{MeHAPCA} \cdot]+[\mathrm{MeOHAPCA}]}
\end{aligned}
$$

The same happens for the mass balance of the aminopolycarboxylic acid ligand:

$$
\begin{aligned}
& C_{A P C A}^{M}=\left[A P C A^{*}\right]+\left[H_{A P C A} \cdot\right]+\left[H_{2} A P C A^{*}\right] \\
& +\left[M e A P C A^{*}\right]+[M e H A P C A \cdot .]+\left[M e O H A P C A^{. *}\right]
\end{aligned}
$$

Please note that many of the species bear a charge. For brevity, when appropriate, two dots (i.e., •.) will be used as placeholders respectively for the size and sign indicating the charge. For instance, APCA $* \equiv \mathrm{APCA}^{n-}$, $\mathrm{MeOH} \cdot \equiv \mathrm{MeOH}^{(\mathrm{z}-1)+}, \mathrm{MeHAPCA} \cdot \equiv \mathrm{MeHAPCA}^{(\mathrm{z}-n+1)-}$, etc...

Using mass balances (12) and (13), condition (4) at the equivalence point becomes:

$$
\begin{aligned}
& {\left[\mathrm{Me}^{\mathrm{z+}}\right]+\left[\mathrm{MeOH}{ }^{*}\right]+\left[\mathrm{Me}(\mathrm{OH})_{2}^{*}\right]+}
\end{aligned}
$$

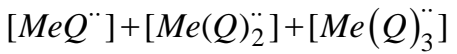

$$
\begin{aligned}
& =\left[A P C A^{. *}\right]+\left[H A P C A^{. *}\right]+\left[H_{2} A P C A^{*}\right]
\end{aligned}
$$

The mass balances (equation (12) and (13)) and the condition (14) at the equivalence point can be written in a 
more compact and convenient form by introducing the notion of group of (chemical) species. A group of species is simply a collection of species existing in the titrated solution.

From equations (12), (13) and (14) we see that the most convenient choice is to define a first group of species,

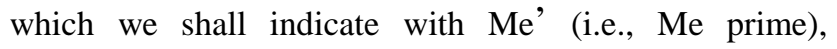
collecting all the species containing the metal cation, $\mathrm{Me}^{\mathrm{z}^{+}}$, but which do not contain the aminopolycarboxylic acid. That is, we define:

$$
\begin{aligned}
& M e^{\prime}=\mathrm{Me}^{\mathrm{Z}+}+\mathrm{MeOH}^{*}+\mathrm{Me}(\mathrm{OH})_{2}{ }^{\cdot} \\
& +\cdots+\mathrm{MeQ}{ }^{*}+\mathrm{Me}(\mathrm{Q})_{2}{ }^{\cdot}+\cdots
\end{aligned}
$$

By definition, the concentration of the Me' group, [Me'], will be:

$$
\begin{aligned}
& {\left[\mathrm{Me}^{\prime}\right]=\left[\mathrm{Me}^{\mathrm{z}}\right]+\left[\mathrm{MeOH}{ }^{*}\right]+\left[\mathrm{Me}(\mathrm{OH})_{2}^{. *}\right]+\ldots+} \\
& +\left[\mathrm{MeQ} \mathrm{Q}^{\cdot]}+\left[\mathrm{Me}(\mathrm{Q})_{2}^{\ddot{*}}\right]+\ldots\right.
\end{aligned}
$$

Analogously, it is convenient to define a second group of species, indicated by APCA' (i.e., APCA prime), collecting all the species in the solution which contain the aminopolycarboxylic acid ligand, but do not contain the metal cation. That is:

$$
A P C A^{\prime}=A P C A^{*}+H A P C A^{*}+H_{2} A P C A^{*}+\cdots
$$

By definition, the concentration of the APCA' group is:

$$
\left[A P C A^{\prime}\right]=\left[A P C A^{*}\right]+\left[H A P C A^{*}\right]+\left[H_{2} A P C A^{*}\right]+\cdots
$$

Finally, we define a complex group of species, MeAPCA', containing the primary complex MeAPCA" plus the basic and acid complexes. We have:

$$
\begin{aligned}
& \text { MeAPCA' }=\text { MeAPCA }{ }^{\prime \prime}+\text { MeHAPCA } \\
& +M e(O H) A P C A^{*}
\end{aligned}
$$

The concentration of the MeAPCA' group, [MeAPCA'], is defined by equation (17):

$$
\begin{aligned}
& {\left[M e A P C A^{\prime}\right]=\left[M e A P C^{*}\right]+\left[M e H A P C A^{. *}\right]} \\
& +[\mathrm{Me}(\mathrm{OH}) \mathrm{APCA} \cdot]
\end{aligned}
$$

With definitions (15) (16) and (17), the mass balances of the metal cation and of the aminopolycarboxylic acid, and the condition at the equivalence point assume the very compact form:

$$
\begin{gathered}
\mathrm{C}_{\mathrm{Me}}^{\mathrm{M}}=\left[\mathrm{Me}^{\prime}\right]+\left[\mathrm{MeAPCA}^{\prime}\right] \\
C_{\mathrm{APCA}}^{\mathrm{M}}=\left[\mathrm{APCA}^{\prime}\right]+\left[\mathrm{MeAPCA}^{\prime}\right] \\
{\left[\mathrm{Me}^{\prime}\right]=\left[\mathrm{APCA}^{\prime}\right]}
\end{gathered}
$$

Thus, the analytical concentration of the metal is given, in each titration point, by the sum of the concentrations of the Me' and MeAPCA' groups; the analytical concentration of the aminopolycarboxylic acid is the sum of the concentrations of the APCA' and MeAPCA' groups of species; finally, the equivalence point of a complexometric titration is reached when the concentrations of the $\mathrm{Me}^{\prime}$ group is equal to that of the APCA' group.

If we now meditate briefly on the above description of the complexometric titration using groups of species and on equations $\left(12_{1}\right),\left(13_{1}\right)$ and $\left(14_{1}\right)$, we realize that this is precisely the same language we would use and relations we would write if in the titrated solution only the single hypothetical reaction (18) took place:

$$
\mathrm{Me}^{\prime}+\mathrm{APCA}^{\prime} \rightleftharpoons \mathrm{MeAPCA}^{\prime}
$$

Reaction (18) is a rather bizarre reaction which exposes as reactants and products groups of species, rather than, as usual, real chemical species.

Nevertheless, we can attribute significance to this strange reaction by convening that it represents any reaction in which any of the species of the Me' group reacts with any of the species belonging to the APCA' group producing any of the species that make up the complex MeAPCA' group of species.

In other words, reaction (18) describes the overall degree of conversion of the metal cation to a complex which contains the aminopolycarboxylic ligand (regardless of the reactants from which this is accomplished and posing no restrictions on the formed complex, except that it must contain the target metal cation and the amino polycarboxylate ligand). Reaction (18) will be called a reaction between groups of species.

We can extend this vision to the reactions of the indicator by simply defining two additional groups of species In' and MeIn'.

The group of species In- is defined in analogy with group APCA- as:

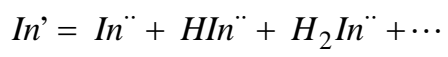

and its concentration is given by equation (19):

$$
\left[\operatorname{In}{ }^{\prime}\right]=[\operatorname{In} \cdot]+\left[\mathrm{HIn}^{. *}\right]+\left[\mathrm{H}_{2} \operatorname{In}^{*}\right]+\ldots
$$

Group MeIn- is analogous to group MeAPCA' and includes, beside the pure complex MeIn" , the acid MeHIn and basic $\mathrm{Me}(\mathrm{OH}) \mathrm{In}$ " complexes, if they are formed.

We have:

$$
\text { MeIn' }=\text { MeIn“ }+ \text { MeHIn“ }+\operatorname{Me}(\mathrm{OH}) \operatorname{In}^{\prime \prime}
$$

And

$$
\begin{aligned}
& {\left[M e A P C A^{\prime}\right]=\left[M e A P C^{. *}\right]+\left[M e H A P C A^{*}\right]} \\
& +[\mathrm{Me}(\mathrm{OH}) \mathrm{APCA} \cdot]
\end{aligned}
$$

These definitions of the groups In' and MeIn' allow us to define in a very simple way the transition point of the metallochromic indicator.

In fact, the indicator transition point coincides with the point of the titration when equal concentrations of In' and MeIn' groups are present in the titrated solution and it is then verified relation (21):

$$
\text { indicator transition point } \rightarrow \frac{[\text { In '] }}{[\text { MeIn'] }}=1
$$

If we meditate about equation (21), which defines the transition point of the indicator, we see that this is exactly 
the expression we would have written if in the titrated solution the only reaction of the indicator was:

$$
\mathrm{Me}^{\prime}+\mathrm{In}{ }^{\prime} \rightleftharpoons \text { MeIn ' }
$$

Reaction (22) is a second reaction between groups of species which, during a complexometric titration, takes place simultaneously with reaction (18).

Finally, we have now developed a formalism which allows a very simple but rigorous description of the chemistry behind a complexometric titration.

During a complexometric titration, only the two reactions between groups of species $\mathrm{Me}^{\prime}+\mathrm{APCA}^{\prime} \rightleftharpoons$ MeAPCA' and Me' + In' $\rightleftharpoons$ MeIn' take place, which exposes five groups of species.

The equivalence point is reached when [Me'] = [APCA'], while the metallochromic indicator reaches its transition point when [In'] $=$ [MeIn'], at which point the solution starts changing colour.

As a general guide, for the accuracy of analytical results derived from the titration, it is necessary that a point of the titration exists in which simultaneously $\left[M e^{\prime}\right] \approx\left[A P C A^{\prime}\right]$ and $\left[\operatorname{In}^{\prime}\right] \approx[$ MeIn']. This is as to say that the change in colour of the indicator must take place as close as possible to the equivalence point.

An indicator which changes colour much before the equivalence point (that is, when $\left[M e^{\prime}\right] \gg\left[A P C A^{\prime}\right]$ ) is said to have low sensitivity for the given titration (and will produce an error in defect on the amount of metal cation determined from the titration). Analogously, it is understood that an indicator with too high sensitivity for the titration at hand changes colour much after the equivalence point (that is when $\left[M e^{\prime}\right] \ll\left[A P C A^{\prime}\right]$ ) and it will produce an error in excess on the amount of metal cation determined from the titration.

Although the sensitivity of the indicator is not the only factor which must be considered, it follows that, for accurate results, at least an indicator of appropriate sensitivity for the planned titration must be at hand.

\subsection{Calculation of the Concentrations of Groups of Chemical Species}

As we have shown in the previous paragraph, one may think that during the titration of a metal cation with an aminopolycarboxylic ligand are formed invariably only five groups of species (i.e., Me', APCA', MeAPCA', In' and MeIn') by two reactions between groups of species.

On the contrary, a variable and relatively large number of individual chemical species (which depends on the nature of the metal cation, on the nature of the aminopolycarboxylic ligand and on the nature of the $\mathrm{pH}$ buffer and indicator) are present in the titrated solution.

As it will become apparent in the following, it is a worth undertaking to extend this picture by evaluating the concentrations of the five groups of species.

In abstract, there are at least two procedures by which the concentrations of the five groups of species in the titrated solution can be evaluated.

Procedure 1. The first way of calculating group concentrations is almost trivial. It consists, in abstract, in using suitable software for calculating the concentrations of the individual species in each point of the titration. The titration data and a long list of reactions with the corresponding equilibrium constants are entered, and the software will output, for any selected value of $V_{\mathrm{t}}^{l}$, an array containing the equilibrium concentration, [...], of each of the species present in the titrated solution. Concentrations in this array are then grouped according to the definitions (15), (16), (17), (19) and (20), and summed to obtain respectively [Me'], [APCA'], [MeAPCA'], [In'], [MeIn'].

Figure 3 represents the outcome of this procedure when applied to the solution presented in Figure 1.

Each bar in Figure 3 (except bars with labels $\mathrm{H}^{+}, \mathrm{OH}^{-}$, $\mathrm{NH}_{3}$, and $\mathrm{NH}_{4}{ }^{+}$) collects several bars of Figure 1 and this is the reason because Figure 3 is much simpler than Figure 1. Nevertheless, Figure 3 gives a great deal of information on the fundamental chemical features of the represented solution.

For instance, we can easily deduce that the overall yield of the primary complex formation reaction is very high, simply because the concentration of the complex group ZnEDTA' is several orders of magnitude larger than the Zn' group concentration. Analogously, we see that the free form of the indicator is largely prevailing on the zincindicator complexes, so that the represented solution exposes the colour of the free indicator.

Furthermore, by confronting Figure 1 with Figure 3, one can get the intriguing idea that they represent, respectively, a high resolution and low resolution view of the chemistry in the considered solution.

The key point is that the low resolution view of the titrated solution is perfectly adequate for practical purposes and, most importantly, can be achieved without employing great means and it is much easier to present.

Procedure 2. The second way for calculating group concentrations only requires $\left[\mathrm{Me}^{\mathrm{z}+}\right]$ for calculating [Me'], [APCA "] for calculating [APCA'], [MeAPCA "] for calculating [MeAPCA'], [In“] for calculating [In'] and [MeIn"] for the calculation of [MeIn'].

Please remember that primed symbols represent groups of chemical species, while symbols bearing double dot (indicating, respectively, size and sign of the charge) represent individual chemical species.

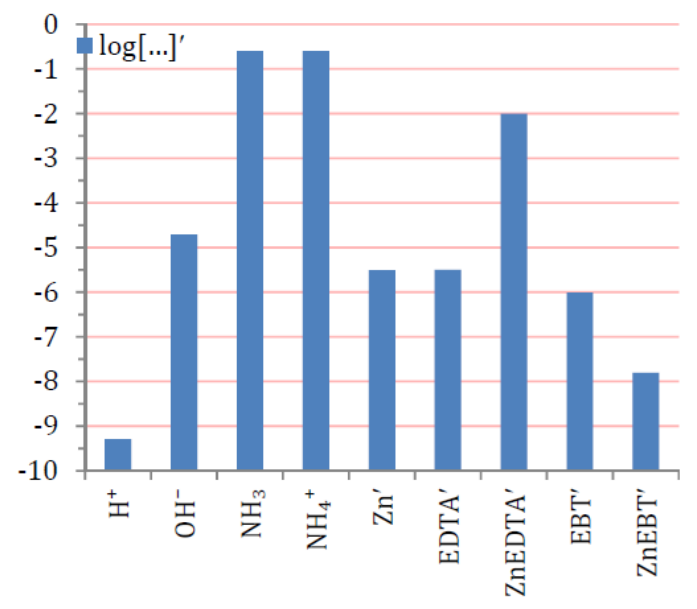

Figure 3. Histogram representing the concentrations of the five groups of chemical species present in a solution $0.01 \mathrm{M} \mathrm{Zn}^{2+}+0.01 \mathrm{M} \mathrm{EDTA}^{4-}$ $+0.25 \mathrm{M} \mathrm{NH}_{3}+0.25 \mathrm{M} \mathrm{NH}_{4}^{+}+10^{-6} \mathrm{M}$ Eriochrome Black $\mathrm{T}$ (the same solution presented in Figure 1). The log of the concentration of a selected group of chemical species can be read in correspondence of the apex of each bar 
In fact, this procedure is based on the use of conversion factors which convert $\left[\mathrm{Me}^{\mathrm{z}+}\right]$ to $\left[\mathrm{Me}^{\prime}\right],\left[\mathrm{APCA}^{\prime \prime}\right]$ to [APCA'] and [MeAPCA '] to [MeAPCA'], etc....

If we indicate these conversion factors, according to a common use $[5,8]$, respectively by $\alpha_{\text {Me }}, \alpha_{\text {APCA }}, \alpha_{\text {MeAPCA }}$ we have:

$$
\begin{gathered}
{\left[\mathrm{Me}^{\prime}\right]=\alpha_{\mathrm{Me}} \cdot\left[\mathrm{Me}^{z+}\right]} \\
{\left[\mathrm{APCA}^{\prime}\right]=\alpha_{\mathrm{APCA}} \cdot\left[\mathrm{APCA}^{\cdot \cdot}\right]} \\
{\left[\mathrm{MeAPCA}^{\prime}\right]=\alpha_{\mathrm{MeAPCA}} \cdot\left[\mathrm{MeAPCA}^{*}\right]}
\end{gathered}
$$

Analogously we have:

$$
\begin{gathered}
{\left[\operatorname{In}^{\prime}\right]=\alpha_{\text {In }} \cdot\left[\operatorname{In}^{. *}\right]} \\
{[\text { MeIn ' }]^{\prime} \alpha_{\text {MeIn }} \cdot[\text { MeIn } “]}
\end{gathered}
$$

Obviously, at first sight this procedure does not appear convenient. In fact, from one side it requires that Procedure1 be executed in order to state the concentrations $\left[\mathrm{Me}^{\mathrm{z}+}\right]$, [APCA ${ }^{\prime \prime}$, [MeAPCA [MeIn "]; and then, in addition, it requires that the alfa conversion factors be evaluated.

Nevertheless, although at present it may not appear clear as the five alfa conversion factors can be evaluated, assume that for a described titration all the five alfa coefficients have a definite value which is the same for all the titration points; in other words, assume that each of the alfa coefficients is constant for a given titration.

Then we can elaborate the equilibrium constants of reactions (5) and (9):

$$
\begin{gathered}
\mathrm{Me}^{\mathrm{z}+}+\mathrm{APCA}^{n-} \rightleftharpoons \operatorname{MeAPCA}^{(n-z)-} \\
\mathrm{Me}^{\mathrm{z}+}+\mathrm{In}^{n-} \rightleftharpoons \operatorname{MeIn}^{(n-z)-}
\end{gathered}
$$

in the following way.

The equilibrium constant of reaction (5) is:

$$
\beta_{1}=\frac{\left[\operatorname{MeAPCA}^{(n-z)-}\right]}{\left[\mathrm{Me}^{\mathrm{z}+}\right]\left[\mathrm{APCA}^{n-}\right]}
$$

From equations (23), (24) and (25) we have:

$$
\begin{gathered}
{\left[\mathrm{Me}^{\mathrm{z}+}\right]=\frac{\left[\mathrm{Me}^{\prime}\right]}{\alpha_{\mathrm{Me}}}} \\
{\left[\text { APCA }^{*}\right]=\frac{\left[\mathrm{APCA}^{\prime}\right]}{\alpha_{\mathrm{APCA}}}} \\
{\left[\mathrm{MeAPCA}^{*}\right]=\frac{\left[\mathrm{MeAPCA}^{\prime}\right]}{\alpha_{\text {MeAPCA }}}}
\end{gathered}
$$

By substituting equations $\left(23_{1}\right),\left(24_{1}\right)$ and $\left(25_{1}\right)$ in the expression of the equilibrium constant (6) and rearranging we have relation (28):

$$
\beta_{1} \frac{\alpha_{\mathrm{MeAPCA}}}{\alpha_{\mathrm{Me}} \cdot \alpha_{\mathrm{APCA}}}=\frac{\left[\mathrm{MeAPCA}^{\prime}\right]}{\left[\mathrm{Me}^{\prime}\right]\left[\mathrm{APCA}^{\prime}\right]}
$$

By assumption, the alfa coefficients are constant for a given titration, so that the left side member of equation (28) is constant during a particular titration.

If we define the parameter $\beta_{1}$ ' (i.e., $\beta_{1}$ prime) as in equation (29):

$$
\beta_{1}{ }^{\prime}=\beta_{1} \frac{\alpha_{\mathrm{MeAPCA}}}{\alpha_{\mathrm{Me}} \cdot \alpha_{\mathrm{APCA}}}
$$

equation (28) can be written in the abridged form:

$$
\beta_{1}^{\prime}=\frac{\left[\mathrm{MeAPCA}^{\prime}\right]}{\left[\mathrm{Me}^{\prime}\right]\left[\mathrm{APCA}^{\prime}\right]}
$$

When the expression of the $\beta_{1}$ ' parameter is confronted with the reaction between groups of species (18):

$$
\mathrm{Me}^{\prime}+\mathrm{APCA}^{\prime} \rightleftharpoons \mathrm{MeAPCA}^{\prime}
$$

we see immediately that expression (30) is precisely what we would have written by applying the law of mass action to the reaction between groups (18).

Then the parameter $\beta_{1}$ ' defined by equation (29) may be understood simply as the equilibrium constant of the reaction between groups Me' + APCA' $\rightleftharpoons$ MeAPCA'.

In order to avoid confusion, we shall call $\beta_{1}$ (which is an equilibrium constant in the usual sense) absolute equilibrium (or formation) constant, while, $\beta_{1}$ ' will be indicated (following a widespread usage $[2,3,5,8]$ ) as conditional equilibrium (or formation) constant.

Analogously, by elaborating the equilibrium constant of reaction (9) on the basis of equations (26) and (27), we obtain:

$$
\beta_{1}^{\mathrm{In}}{ }^{\prime}=\beta_{1}^{\mathrm{In}} \frac{\alpha_{\mathrm{MeIn}}}{\alpha_{\mathrm{Me}} \cdot \alpha_{\mathrm{In}}}=\frac{\left[\mathrm{MeIn}{ }^{\prime}\right]}{\left[\mathrm{Me}^{\prime}\right]\left[\mathrm{In}^{\prime}\right]}
$$

in which $\beta_{1}{ }^{\text {In }}$ (i.e., $\beta_{1}{ }^{\text {In }}$ prime) represents the equilibrium constant of the reaction between groups $\mathrm{Me}^{\prime}+\mathrm{In}{ }^{\prime} \rightleftharpoons$ MeIn' (that is, the conditional formation constant of the metal-indicator complex).

The usefulness of the above elaborations depends on the fact that, if, for a given titration, constant values for the conditional constants exist and if we are able to evaluate them, then we can calculate the group concentrations precisely as if they were single species concentrations and treat the reactions between groups of species as if they were standard reactions between species.

In fact, if constants values of the conditional constants can be secured, we can write as many relations between the groups of species in the titrated solution as the number of groups of species, and solve the ensuing system of equations to obtain the concentrations of the groups.

The system of equations for calculating the groups concentrations [Me'], [APCA'] and [MeAPCA'] is made up by the two mass balance equations $\left(12_{1}\right)$ and $\left(13_{1}\right)$ and by the expression (30) of the conditional formation constant of the reaction between groups $\mathrm{Me}^{\prime}+\mathrm{APCA}^{\prime} \rightleftharpoons$ MeAPCA'. We have:

$$
\begin{gathered}
\frac{C_{0}^{\mathrm{M}} \cdot V_{0}^{l}}{V_{\mathrm{t}}^{l}+V_{0}^{l}}=\left[\mathrm{Me}^{\prime}\right]+\left[\mathrm{MeAPCA}^{\prime}\right] \\
\frac{C_{\mathrm{t}}^{\mathrm{M}} \cdot V_{\mathrm{t}}^{l}}{V_{\mathrm{t}}^{l}+V_{0}^{l}}=\left[\mathrm{APCA}^{\prime}\right]+\left[\mathrm{MeAPCA}^{\prime}\right]
\end{gathered}
$$




$$
\beta_{1}^{\prime}=\frac{\left[\mathrm{MeAPCA}^{\prime}\right]}{\left[\mathrm{Me}^{\prime}\right]\left[\mathrm{APCA}^{\prime}\right]}
$$

The mass balances $\left(12_{2}\right)$ and $\left(13_{2}\right)$ have been derived from the mass balances $\left(12_{1}\right)$ and $\left(13_{1}\right)$ by using relations (2) for $C_{\mathrm{APCA}}^{\mathrm{M}}$ and relation (3) for $C_{\mathrm{Me}}^{\mathrm{M}}$.

Although the above procedure for obtaining the system of equations $\left(12_{2}\right)+\left(13_{2}\right)+(30)$ may appear tedious, it must be understood that, for any assumed value of $V_{t}^{l}$, we can obtain the concentrations of the three groups of species [Me'], [APCA'] and [MeAPCA'] in the solution by solving this system of three equations (whatever may be the complexometric titration and however large it can be the number of individual species in the titrated solution).

The form of this system is always the same for all titrations, although, of course, the values of the various parameters and the symbols representing the metal and the aminopolycarboxylic acid ligand may change from titration to titration.

In $\S 3.2$ are presented directives on how a MS Excel sheet, for solving the above system of equation, can be developed.

Please note that we have not considered the problem of calculating [In'] and [MeIn'] since this is in practice irrelevant.

In fact, in order to evaluate the sensitivity of the indicator, it is only required the conditional constant for the reaction between groups $\mathrm{Me}$ ' $+\mathrm{In}^{\prime} \rightleftharpoons \mathrm{MeIn}$ ' (i.e.,

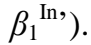

In the next paragraph we face in detail the problem of evaluating, for a described titration, the $\beta_{1}{ }^{\text {' }}$ and $\beta_{1}{ }^{\text {In, }}$ conditional formation constants.

\subsection{Evaluation of the Conditional Formation Constants, $\beta_{1}$ ' and $\beta_{1}{ }^{\text {In, }}$}

The evaluation of the conditional formation constant, $\beta_{1}^{\prime}$, which governs the reaction between groups of species $\mathrm{Me}^{\prime}+\mathrm{APCA}^{\prime} \rightleftharpoons$ MeAPCA' is based on the evaluation of the $\alpha_{\mathrm{Me}}, \alpha_{\mathrm{APCA}}, \alpha_{\mathrm{MeAPCA}}$ coefficients whose values are then substituted into equation (29):

$$
\beta_{1}^{\prime}=\beta_{1} \frac{\alpha_{\mathrm{MeAPCA}}}{\alpha_{\mathrm{Me}} \cdot \alpha_{\mathrm{APCA}}}
$$

From this, it should be clear that the absolute formation constant, $\beta_{1}$, must be known.

As a matter of fact, in order to evaluate the alfa coefficients, all the reactions which take place in the titrated solution (and the corresponding equilibrium constants) must be known.

For example, for the titration of the $\mathrm{Zn}^{2+}$ cation with EDTA in an ammoniacal buffer a list of reactions and equilibrium constants as the one presented in Table 1 must be at hand.

In order to develop general relations which allow the evaluation of the alfa coefficients, it is useful to write the relevant side reactions in a general form (see Figure 2).

The ubiquitous hydroxo complexes of the metal cation are supposed to be formed according to the general reaction (32):

$$
\mathrm{Me}^{\mathrm{z}+}+m \mathrm{OH}^{-} \rightleftharpoons \mathrm{Me}(\mathrm{OH})_{m}^{(m-z)-} \rightarrow \beta_{m}^{\mathrm{OH}}
$$

For specific examples of reaction (32) when $\mathrm{Me}^{\mathrm{z+}}=$ $\mathrm{Zn}^{2+}$, see Table 1 .

From the expression of the equilibrium constant, $\beta_{m}^{\mathrm{OH}}$, of reaction (32), we readily obtain relation (33) for the concentaration $\left[\mathrm{Me}(\mathrm{OH})_{m}^{(m-z)-}\right]$ of the general hydroxo complex:

$$
\left[\mathrm{Me}(\mathrm{OH})_{m}^{(m-z)-}\right]=\beta_{m}^{\mathrm{OH}}\left[\mathrm{Me}^{\mathrm{z}+}\right]\left[\mathrm{OH}^{-}\right]^{m}
$$

If the auxiliary ligand is indicated by the symbol Q“ $\equiv$ $\mathrm{Q}^{n-}$ (e.g., $\mathrm{Q}^{*}=\mathrm{NH}_{3}$ ), the side reactions of $\mathrm{Me}^{\mathrm{Z+}}$ with $\mathrm{Q}$. are of the general form (34):

$$
M e^{Z+}+q Q^{*} \rightleftharpoons \operatorname{Me}(Q)_{q}^{*} \rightarrow \beta_{q}^{Q}
$$

For specific examples of reaction (34), when Q" $=\mathrm{NH}_{3}$ and $\mathrm{Me}^{\mathrm{Z}^{+}}=\mathrm{Zn}^{2+}$, see Table 1 .

From the expression of the equilibrium constant, $\beta_{q}^{\mathrm{Q}}$, of reaction (34), we readily obtain relation (35) for the concentaration $\left[\mathrm{Me}(\mathrm{Q})_{q}^{*}\right]$ of the general $\operatorname{Me}(\mathrm{Q})_{q}^{*}$ complex:

$$
\left[\operatorname{Me}(Q)_{q}^{*}\right]=\beta_{q}^{Q}\left[M e^{Z+}\right]\left[Q^{*}\right]^{q}
$$

Furthermore, the side reactions of protonation of the aminopolycarboxylic acid ligand, $\mathrm{APCA}^{n-} \equiv$ APACA“", are described by the general reaction (36):

$$
\mathrm{APCA}^{*}+h \mathrm{H}^{+} \rightleftharpoons \mathrm{H}_{h} \mathrm{APCA}^{*} \rightarrow \beta_{h}^{\mathrm{APCA}}
$$

See Table 1 for specific examples of reaction (36), when $\mathrm{APCA}^{*}=\mathrm{EDTA}^{4-}$.

From the expression of the protonation constants of the aminopolycarboxylic acid we readily obtain:

$$
\left[H_{h} A P C A^{*}\right]=\beta_{h}^{A P C A}\left[A P C A^{*}\right]\left[H^{+}\right]^{h}
$$

Finally, acid and basic complexes are formed from the primary complex MeAPCA ${ }^{(n-z)-} \equiv$ MeAPCA $^{*}$ according to reactions (38) and (39):

$$
\begin{gathered}
\text { MeAPCA }^{*}+\mathrm{H}^{+} \rightleftharpoons \text { MeHAPCA }^{*} \rightarrow \beta_{\mathrm{H}}^{\text {MeAPCA }} \\
\text { MeAPCA }^{*}+\mathrm{OH}^{-} \rightleftharpoons \mathrm{Me}(\mathrm{OH}) \text { APCA }^{*} \rightarrow \beta_{\mathrm{OH}}^{\text {MeAPCA }}
\end{gathered}
$$

See Table 1, for specific examples of reactions (38) and (39), when MeAPCA ${ }^{*}=$ ZnEDTA $^{2-}$.

From the expressions of the equilibrium constants of reactions (38) and (39) we readily obtain:

$$
\begin{gathered}
{[\mathrm{MeHAPCA}]=\beta_{H}^{M e A P C A}[\mathrm{MeAPCA}]\left[\mathrm{H}^{+}\right]} \\
{[\mathrm{Me}(\mathrm{OH}) \mathrm{APCA} \cdot]=\beta_{\mathrm{OH}}^{\mathrm{MeAPCA}}[\mathrm{MeAPCA}]\left[\mathrm{OH}^{-}\right]}
\end{gathered}
$$

By substituting expressions (33) and (35) into relation (15) which defines the Me' group concentration we have:

$$
\left[\mathrm{Me}^{\prime}\right]=\left[\mathrm{Me}^{\mathrm{Z}+}\right]\left(\begin{array}{l}
1+\sum\left[\beta_{m}^{\mathrm{OH}}\right]\left[\mathrm{OH}^{-}\right]^{m} \\
+\sum \beta_{q}^{Q}\left[Q^{*}\right]^{q}
\end{array}\right)
$$


Analogously, by using expression (37) into equation (16) which defines the APCA' group concentration we have:

$$
\left[\mathrm{APCA}^{\prime}\right]=\left[\mathrm{APCA}^{\cdot \cdot}\right]\left(1+\sum \beta_{h}^{\mathrm{APCA}}\left[\mathrm{H}^{+}\right]^{h}\right)
$$

Finally, we substitute expressions (40) and (41) for the concentration of the acid and basic complexes into relation (17) which defines the MeAPCA' group concentration and readily obtain relation (44):

$$
\left[\mathrm{MeAPCA}^{\prime}\right]=\left[\mathrm{MeAPCA}^{. \cdot}\right]\left(\begin{array}{l}
1+\beta_{\mathrm{H}}^{\mathrm{MeAPCA}}\left[\mathrm{H}^{+}\right] \\
+\beta_{\mathrm{OH}}^{\mathrm{MeAPCA}}\left[\mathrm{OH}^{-}\right]
\end{array}\right)
$$

If the above relations (42), (43) and (44) are confronted with relations (23), (24) and (25), which define the alfa coefficients, we immediately see that:

$$
\begin{gathered}
\alpha_{\mathrm{Me}}=\left(1+\sum\left[\beta_{m}^{\mathrm{OH}}\right]\left[\mathrm{OH}^{-}\right]^{m}+\sum \beta_{q}^{Q}\left[Q^{*}\right]^{q}\right) \\
\alpha_{\mathrm{APCA}}=\left(1+\sum \beta_{h}^{\mathrm{APCA}}\left[\mathrm{H}^{+}\right]^{h}\right) \\
\alpha_{\mathrm{MeAPCA}}=\left(1+\beta_{\mathrm{H}}^{\mathrm{MeAPCA}}\left[\mathrm{H}^{+}\right]+\beta_{\mathrm{OH}}^{\mathrm{MeAPCA}}\left[\mathrm{OH}^{-}\right]\right)
\end{gathered}
$$

Relations (45), (46) and (47) are what it is needed for calculating the coefficients $\alpha_{\mathrm{Me}}, \alpha_{\mathrm{APCA}}$ and $\alpha_{\mathrm{MeAPCA}}$.

In order to calculate the conditional constant for the formation of the metal-indicator complexes from relation (31), only the alfa coefficients $\alpha_{\text {In }}$ and $\alpha_{\text {MeIn }}$ must be evaluated (since $\alpha_{\mathrm{Me}}$ is already expressed from equation (45)).

$\alpha_{\text {In }}$ is very similar to $\alpha_{\text {APCA }}$ and depends on the protonation constants of the indicator according to relation (48)

$$
\alpha_{\mathrm{In}}=\left(1+\sum \beta_{h}^{\mathrm{In}}\left[\mathrm{H}^{+}\right]^{h}\right)
$$

in which $\beta_{h}^{\text {In }}$ represents the equilibrium constant for the general reaction of protonation of the indicator:

$$
\mathrm{In}^{n-}+h \mathrm{H}^{+} \rightleftharpoons \mathrm{H}_{h} \mathrm{In}^{(n-h)-} \rightarrow \beta_{h}^{\text {In }}
$$

$\alpha_{\text {MeIn }}$ is very similar to $\alpha_{\text {MeAPCA }}$ and depends on the formation constants of acid or basic complexes $\mathrm{MeHIn}^{(n-z-}$ 1)- $\equiv$ MeHIn $^{*}$ and MeOHIn ${ }^{(n-z+1)-} \equiv$ MeOHIn " (if they are described).We have:

$$
\alpha_{\mathrm{MeIn}}=\left(1+\beta_{\mathrm{H}}^{\mathrm{MeIn}}\left[\mathrm{H}^{+}\right]+\beta_{\mathrm{OH}}^{\mathrm{MeIn}}\left[\mathrm{OH}^{-}\right]\right)
$$

$\beta_{\mathrm{H}}^{\mathrm{MeIn}}$ and $\beta_{\mathrm{OH}}^{\mathrm{MeIn}}\left[\mathrm{OH}^{-}\right]$are the equilibrium constants of reactions (51) and (52), respectively:

$$
\begin{gathered}
\text { MeIn }{ }^{*}+\mathrm{H}^{+} \rightleftharpoons \text { MeHIn }{ }^{*} \rightarrow \beta_{\mathrm{H}}^{\text {MeIn }} \\
\text { MeIn" }+\mathrm{OH}^{-} \rightleftharpoons \text { MeOHIn }{ }^{\circ} \rightarrow \beta_{\mathrm{OH}}^{\mathrm{MeIn}}
\end{gathered}
$$

Although the above derivation may appear tedious, all it is necessary to understand it is that the five alfa conversion factors are expressed by relations (45), (46), (47), (48) and (50), which are collected in Table 2, where are also rewritten the relations which connect the absolute formation constants, $\beta_{1}$ and $\beta_{1}{ }^{\text {In }}$, to the corresponding conditional constants, $\beta_{1}{ }^{\text {' }}$ and $\beta_{1}{ }^{\text {In, }}$, through the five alfa conversion factors.

As a matter of fact, Table 2 contains all the necessary relations for understanding and using the notions of groups of species and reactions between groups of species, which allow a simple but rigorous description of a complexometric titration.

Table 2. General relations to be used for calculating alfa conversion factors and conditional formation constants $\beta_{1}$ ' and $\beta_{1}{ }^{\text {In, }}$.

$$
\begin{gathered}
\alpha_{\mathrm{Me}}=\left(1+\sum\left[\beta_{m}^{\mathrm{OH}}\right]\left[\mathrm{OH}^{-}\right]^{m}+\sum \beta_{q}^{Q}\left[Q^{*}\right]^{q}\right)(45) \\
\alpha_{\mathrm{APCA}}=\left(1+\sum \beta_{h}^{\mathrm{APCA}}\left[\mathrm{H}^{+}\right]^{h}\right)(46) \\
\alpha_{\mathrm{MeAPCA}}=\left(1+\beta_{\mathrm{H}}^{\mathrm{MeAPCA}}\left[\mathrm{H}^{+}\right]+\beta_{\mathrm{OH}}^{\mathrm{MeAPCA}}\left[\mathrm{OH}^{-}\right]\right)(47) \\
\alpha_{\mathrm{In}}=\left(1+\sum \beta_{h}^{\mathrm{In}}\left[\mathrm{H}^{+}\right]^{h}\right)(48) \\
\alpha_{\mathrm{MeIn}}=\left(1+\beta_{\mathrm{H}}^{\mathrm{MeIn}}\left[\mathrm{H}^{+}\right]+\beta_{\mathrm{OH}}^{\mathrm{MeIn}}\left[\mathrm{OH}{ }^{-}\right]\right)(50) \\
\beta_{1}^{\prime}=\beta_{1} \frac{\alpha_{\mathrm{MeAPCA}}}{\alpha_{\mathrm{Me}} \cdot \alpha_{\mathrm{APCA}}}(29) \\
\beta_{1}^{\mathrm{In}}{ }^{\prime}=\beta_{1}^{\mathrm{In}} \frac{\alpha_{\mathrm{MeIn}}}{\alpha_{\mathrm{Me}} \cdot \alpha_{\mathrm{In}}}(31)
\end{gathered}
$$

Even a superficial inspection of Table 2 will show that the fundamental requirement for the alfa coefficients to be constant during a titration is that the $\mathrm{pH}$ of the titrated solution be constant throughout the titration. However, this does not represent an additional constraint for the execution of the complexometric titration since, as we have anticipated in the introduction, a constant $\mathrm{pH}$ of the titrated solution must be maintained in any case to control the behaviour of the metallochromic indicator.

A further condition is that, to keep constant $\alpha_{\text {Me }}$, the equilibrium concentration of the auxiliary ligand, [Q**], also must not appreciably change during the titration. This condition is generally not satisfied during a practical titration. In fact the addition of the titrant will dilute the components of the $\mathrm{pH}$ buffer. Although this, in general, has no effect on the $\mathrm{pH}$ of the titrated solution, [Q**] steadily decreases during the titration. This implies that $\alpha_{\mathrm{Me}}$ decreases and the conditional formation constants increase somewhat during a practical titration (see relation (45), (29) and (31) in Table 1). This effect largely depends on the conditions of a particular titrations and will be neglected in the following since experience shows that it has, in most practical cases, minor effects on predictions. In general, the initial value of $\left[\mathrm{Q}^{*}\right]$ can be used for evaluations.

Another important point to be stressed is the fact that all the alfa coefficients are $\geqq 1$.

$\alpha_{\text {Me }}$ invariably increases by increasing the $\mathrm{pH}$ and the concentration of the auxiliary ligand because this favours the side reactions of the metal cation. This increase of $\alpha_{\mathrm{Me}}$ will produce a corresponding decrease of the conditional formation constants. 
On the contrary, $\alpha_{\mathrm{APCA}}$ and $\alpha_{\text {In }}$ will always increase by decreasing the $\mathrm{pH}$ and this effect will tend to decrease the value of the conditional constants as the $\mathrm{pH}$ of the titrated solution is decreased.

$\alpha_{\text {MeAPCA }}$ and $\alpha_{\text {MeIn }}$ will be in general very close to one because acid and basic complexes are only formed at extreme $\mathrm{pH}$, while practical complexometric titrations are performed in the range $\sim 4<\mathrm{pH}<\sim 12$. This is necessary in order to avoid the unfavourable effects due to the drop of $\beta_{1}$ ' and of $\beta_{1}^{\text {In, }}$ that generally takes place at very low and very high $\mathrm{pH}$.

\section{Use of Group Concentrations and Reactions between Groups of Species}

After the elaborations in the previous paragraph, we are now in a position to perform all the necessary evaluations concerning any complexometric titration by completely ignoring (after the alfa conversion factors and the values of the two conditional constants have been evaluated) the plethora of reactions and species that are present in the titrated solution.

In fact, in order to expose the analytically relevant aspects of the complexometric titration, we only need to assume that in the titrated solution are present the five groups of species [Me'], [APCA'], [MeAPCA'], [In'], [MeIn'] that are formed by the two reactions between groups of species:

$$
\begin{gathered}
\mathrm{Me}^{\prime}+\mathrm{APCA}^{\prime} \rightleftharpoons \mathrm{MeAPCA}^{\prime} \rightarrow \beta_{1}^{\prime} \\
\mathrm{Me}^{\prime}+\mathrm{In}^{\prime} \rightleftharpoons \mathrm{MeIn}^{\prime} \rightarrow \beta_{1}^{\mathrm{In}},
\end{gathered}
$$

which are governed by the two conditional equilibrium constants $\beta_{1}$ ' and $\beta_{1}{ }^{\text {In, }}$ (whose values have been evaluated as described in the previous paragraph).

\subsection{Complexometric Titration Curves}

In the framework of the model of groups of species and reactions between groups of species, the titration curve for a complexometric titration is the plot representing log[Me'] as a function of $V_{\mathrm{t}}^{l}$; or the plot of $\log \left[\mathrm{APCA}^{\prime}\right]$ as a function of $V_{\mathrm{t}}^{l}$; or a plot which contains both the $\log \left[\mathrm{Me}^{\prime}\right] \rightarrow V_{\mathrm{t}}^{l}$ and $\log \left[\mathrm{APCA}^{\prime}\right] \rightarrow V_{\mathrm{t}}^{l}$ curves.

In abstract, titration curves can be calculated by the following procedure.

First, from the titration parameters (i.e., $C_{\mathrm{t}}^{\mathrm{M}}, C_{0}^{\mathrm{M}}, V_{\text {eq }}^{l}$, $\beta_{1}$ ' and $\beta_{1}^{\text {In') }}$ and from equation (1) we calculate the equivalent volume. We have:

$$
V_{\mathrm{eq}}^{l}=\frac{C_{0}^{\mathrm{M}} \cdot V_{0}^{l}}{C_{\mathrm{t}}^{\mathrm{M}}}
$$

Then, we select an array of $V_{t}^{l}$ values covering the range $0 \leqq V_{\mathrm{t}}^{l} \leqq \sim 2 \cdot V_{\mathrm{eq}}^{l}$, (it is convenient to change from $V_{\mathrm{t}}^{l}$ to $V_{\mathrm{t}}(\mathrm{ml})$ since volumes read on burettes are in millilitres).

For each of the selected $V_{\mathrm{t}}(\mathrm{ml})$, we obtain the concentrations of the groups of species [Me'], [APCA'] and [MeAPCA'] in the titrated solution by solving the system of three equations:

$$
\begin{gathered}
\frac{C_{0}^{\mathrm{M}} \cdot V_{0}^{l}}{V_{\mathrm{t}}^{l}+V_{0}^{l}}=\left[\mathrm{Me}^{\prime}\right]+\left[\mathrm{MeAPCA}^{\prime}\right] \\
\frac{C_{\mathrm{t}}^{\mathrm{M}} \cdot V_{\mathrm{t}}^{l}}{V_{\mathrm{t}}^{l}+V_{0}^{l}}=\left[\mathrm{APCA}^{\prime}\right]+\left[\mathrm{MeAPCA}^{\prime}\right] \\
\beta_{1}^{\prime} \rightleftharpoons \frac{\left[\mathrm{MeAPCA}^{\prime}\right]}{\left[\mathrm{Me}^{\prime}\right]\left[\mathrm{APCA}^{\prime}\right]}
\end{gathered}
$$

A matrix of numbers, which we shall call $<$ MyTitrationMatrix $>$, is created by transferring, in the order of increasing $V_{\mathrm{t}}(\mathrm{ml})$, each calculated array of values $\left\{V_{\mathrm{t}}(\mathrm{ml}), \log \left[\mathrm{Me} \mathrm{e}^{\prime}\right], \log \left[\mathrm{APCA}^{\prime}\right], \log \left[\mathrm{MeAPCA}{ }^{\prime}\right]\right\}$, in a line of a spreadsheet (e.g. MS Excel).

$<$ MyTitrationMatrix $>$ has four columns (identified by symbols $V_{\mathrm{t}}(\mathrm{ml}), \log \left[\mathrm{Me}\right.$ '], $\left.\log \left[\mathrm{APCA}^{\prime}\right], \log [\mathrm{MeAPCA}]\right)$ and each line of the matrix (specified by the value of $V_{\mathrm{t}}(\mathrm{ml})$ ) represents a point of the titration.

After $<$ MyTitrationMatrix $>$ has been compiled, it is a simple matter to draw a plot exposing curves $\log \left[\mathrm{Me}^{\prime}\right] \rightarrow V_{\mathrm{t}}(\mathrm{ml}), \quad \log \left[\mathrm{APCA}^{\prime}\right] \rightarrow V_{\mathrm{t}}(\mathrm{ml})$ (and eventually $\left.\log [\mathrm{MeAPCA}] \rightarrow V_{\mathrm{t}}(\mathrm{ml})\right)$.

Obviously, at first sight, this procedure appears rather tedious, because one needs to solve the system of equations $\left(12_{2}\right),\left(13_{2}\right)$ and (30) for each of the selected values of $V_{\mathrm{t}}(\mathrm{ml})$. However, in the next paragraph, it is shown how to develop an MS Excel file which will create $<$ MyTitrationMatrix $>$ in a matter of minutes.

Aside from that, in Figure 4 it is presented such a plot drawn assuming the following typical representative values for the titration data: $C_{\mathrm{t}}^{\mathrm{M}}=0.0200 ; C_{0}^{\mathrm{M}}=0.0100$; $V_{0}^{\mathrm{ml}}=50.0 ; \beta_{1}{ }^{\prime}=10^{8}$ and $\beta_{1}{ }^{\mathrm{In}}=10^{4}$.

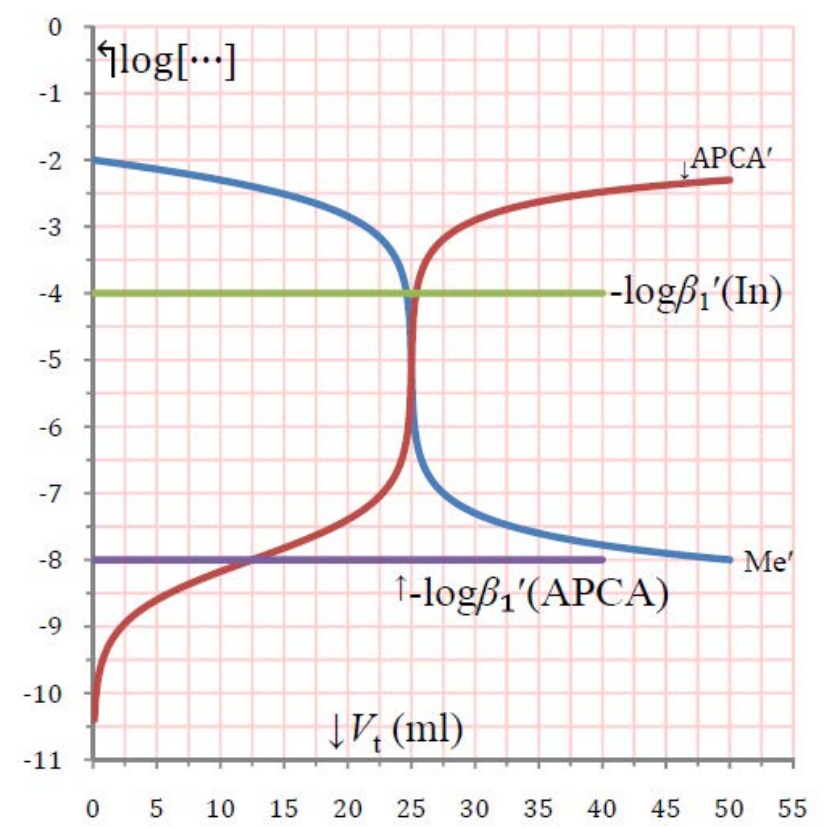

Figure 4. Complexometric titration curves $\log [\mathrm{Me}] \rightarrow V_{\mathrm{t}}(\mathrm{ml})$ and $\log \left[\right.$ APCA' $\left.^{\prime}\right] V_{\mathrm{t}}(\mathrm{ml})$ calculated with the following titration parameters: $C_{\mathrm{t}}^{\mathrm{M}}=0.0200 ; C_{0}^{\mathrm{M}}=0.0100 ; V_{0}^{\mathrm{ml}}=50.0 ; \beta_{1}{ }^{\prime}=10^{8}$. Furthermore, horizontal lines of ordinate $-\log \left(\beta_{1}{ }^{\text {In }}\right)=-4$ and $-\log \left(\beta_{1}{ }^{\prime}\right)=-8$ (whose significance is explained in the text) have been drawn 
It must be realized that, in the frame of the model of groups of species and reactions between groups of species, the specific nature of the metal cation and of the aminopolycarboxylic acid ligand (and indicator) are completely immaterial: the titration of $50 \mathrm{ml}$ of a $0.01 \mathrm{M}$ solution, of whatsoever metal cation, with a $0.02 \mathrm{M}$ standard solution of any aminopolycarboxylic acid ligand, under conditions that happen to produce a value of the conditional constant $\beta_{1}{ }^{\prime}=10^{8}$, will be represented by Figure 4 (with obvious variations in the symbols representing the metal cation and the aminopolycarboxylic ligand).

From Figure 4 we can easily see that the equivalent volume is $V_{\text {eq }}=25.00 \mathrm{ml}$, corresponding to the crossing point between curves representing APCA' and Me' $\left(V_{\text {eq }}\right.$ can be read precisely from $<$ MyTitrationMatrix $>$ in correspondence of the line where the relation log[APCA'] $=\log \left[\mathrm{Me}^{\prime}\right]$ is verified). Moreover, at the equivalence point $\log \left[\mathrm{Me}^{\prime}\right]_{\mathrm{eq}}=\log \left[\mathrm{APCA}^{\prime}\right]_{\mathrm{eq}}=-5.1$.

In the plot, two additional horizontal lines, whose ordinates are $-\log \left(\beta_{1}{ }^{\text {In }}\right)$ and $-\log \left(\beta_{1}{ }^{\prime}\right)$ respectively, have been drawn. Please note that, in Figure $4, \beta_{1}{ }^{\text {In }} \equiv \beta_{1}$ '(In) and $\beta_{1}$ ’ $\beta_{1}$ '(APCA).

Line labelled $-\log \beta_{1}$ '(In) corresponds to the value of $\log [\mathrm{Me}$ '] for which equal concentrations of MeIn' and In' are present in the solution

This is easily understood on the basis of the expression of the conditional constant for reaction Me' + In' $\rightleftharpoons$ MeIn':

$$
\beta_{1}^{\mathrm{In}}{ }^{\prime} \rightleftharpoons \frac{\left[\mathrm{MeIn}^{\prime}\right]}{\left[\mathrm{Me}^{\prime}\right]\left[\mathrm{In}^{\prime}\right]}
$$

The logarithmic form of equation (31) is:

$$
-\log \left[\mathrm{Me}^{\prime}\right]-\log \beta_{1}^{\mathrm{In}}{ }^{\prime}=\log \frac{\left[\mathrm{In}^{\prime}\right]}{[\text { MeIn'] }}
$$

From $\left(31_{1}\right)$, it is quite apparent that when $\log \left[\mathrm{Me}^{\prime}\right]=$ $\log \left(\beta_{1}{ }^{\text {In }}\right)$ then [In']/[MeIn'] $=1$. That is, the horizontal line labelled $-\log \beta_{1}$ '(In) in Figure 4 represents the transition point of the indicator.

Nevertheless, in order to see the pure colour of In', it will be necessary to proceed somewhat further the transition point, for instance, to reach an [Me'] value for which $\left[\right.$ In']/[MeIn'] $\approx 10$. From equation $\left(31_{1}\right)$, we see that this will happen when $\left.\log \left[\mathrm{Me} \mathrm{e}^{\prime}\right] \approx\left(-\log \left(\beta_{1}{ }^{\mathrm{In}}\right)\right)-1\right)$.

In the case of Figure 4 this implies that the titration will be stopped when $\log \left[\mathrm{Me}^{\prime}\right] \approx-4-1=-5$.

Evidently, an indicator for which $\beta_{1}^{\text {In, }}=10^{4}$ is almost ideal for the titration of Figure 4.

As can be judged from the value of $\beta_{1}{ }^{\prime}=10^{8}$ (and from the position of the line labelled, $-\log \beta_{1}$ '(APCA) in Figure 4) the indicator appropriate for a given complexometric titration must have, under the conditions of the titration, $\beta_{1}{ }^{\text {In, }} \quad<\beta_{1}$ '. This is obvious, since the aminopolycarboxylic ligand must be able to attack and decompose the MeIn' complex through the reaction between groups:

$$
\text { MeIn '+ APCA ' } \rightleftharpoons \text { MeAPCA ' }+ \text { In ' } \rightarrow K=\beta_{1}{ }^{\prime} / \beta_{1}^{\text {In } ~}
$$

and this will happen only if $\beta_{1}{ }^{\prime} \gg \beta_{1}{ }^{\text {In, }}$.

From Figure 4 we see that, under typical conditions, a metallochromic indicator for which $\log \left(\beta_{1}{ }^{\text {In }}\right) \approx 1 / 2 \log \left(\beta_{1}{ }^{\prime}\right)$ has an appropriate sensitivity (i.e., it changes colour close to the equivalence point).

Please note that, since both $\beta_{1}{ }^{\text {In, }}$ and $\beta_{1}$ ' will change, especially by changing the $\mathrm{pH}$ and the nature and concentration of the buffer in the titrated solution, a metallochromic indicator which is suitable for a given titration under certain conditions, can become completely unsatisfying if, for instance, the $\mathrm{pH}$ of the titrated solution is modified.

The accuracy of results derived from a complexometric titration also fundamentally depends on the value of the conditional constant, $\beta_{1}$ ', of the reaction between groups $\mathrm{Me}^{\prime}+\mathrm{APCA}^{\prime} \rightleftharpoons \mathrm{MeAPCA}$ '.

This is because, hardly, if ever, it will be possible to select a metallochromic indicator which changes colour exactly at the equivalence point, i.e., when [Me'] = $[\mathrm{Me}]_{\mathrm{eq}}$. This implies that the volume, $V_{\text {arr }}(\mathrm{ml})$, which we read on the burette when the titration is ended (and which is used instead of $V_{\text {eq }}(\mathrm{ml})$ in all evaluations) does, as a matter of fact, differ from $V_{\mathrm{eq}}(\mathrm{ml})$. A reasonable standard of accuracy is to pretend that $\left|V_{\text {eq }}-V_{\text {arr }}\right| \leqq 0.1 \mathrm{ml}$, which is about the precision of volumes delivered by a burette.

If we follow the curve representing Me' in Figure 4 and if we indicate with [Me'] $]_{-0.1}$ the value of [Me'] when a volume of titrant equal to $V_{\text {eq }}-0.1 \mathrm{ml}$ has been added, we find $\log \left[\mathrm{Me}^{\prime}\right]_{-0.1}=-4.54$. Analogously, if we indicate with $\left[\mathrm{Me}^{\prime}\right]_{+0.1}$ the value of [Me'] when a volume of titrant equal to $V_{\text {eq }}+0.1 \mathrm{ml}$ has been added, we find $\log [\mathrm{Me}]_{+0.1}$ $=-5.64$. It follows that, in the case presented in Figure 4, we can stop the titration anywhere in the range $-5.64<$ $\log \left[\mathrm{Me}^{\prime}\right]<-4.54$, without the difference $\left|V_{\text {eq }}-V_{\text {arr }}\right|$ exceeding $0.1 \mathrm{ml}$. Then, we can meet our standard of accuracy using whatever metallochromic indicator which has, under the condition of the titration, $\sim 3.54<\log \left(\beta_{1}{ }^{\text {In }}\right)$ $<\sim 4.64$.

From this we deduce that, around the equivalent point, there is an interval which has the following property: if the titration is stopped in this interval, then, the error on the volume measured from the titration does not exceed 0.1 $\mathrm{ml}$. The fact is that the amplitude of this interval depends on the value of $\beta_{1}$ '.

This interval is already somewhat narrow when, as in Figure $4, \beta_{1}{ }^{\prime}=10^{8}$ (about one $\log$ unit) and becomes increasingly narrower as $\beta_{1}$ ' decreases. As a consequence, if the $\beta_{1}$ ' value drops under the threshold of about $10^{8}$, it may be extremely difficult or impossible to find an appropriate indicator which allows the set standard of accuracy to be met. This is especially true in view of the fact that the number of metallochromic indicators available is limited.

For instance, Figure 5 presents a complexometric titration performed with the same parameters as titration in Figure 4, except that $\beta_{1}{ }^{\prime}=10^{6}$ has been assumed.

This titration hardly will provide accurate results.

By following the Me' curve in Figure 5, we see that at the equivalence point (at $V_{\mathrm{t}}=25.0 \mathrm{ml}$ ) $\log \left[\mathrm{Me}^{\prime}\right]_{\mathrm{eq}}=-4.09$.

On the other side, we have $\log \left[\mathrm{Me}^{\prime}\right]_{-0.1}=-4.02$ and $\log \left[\mathrm{Me}^{\prime}\right]_{+0.1}=-4.16$. In order for this titration to meet our standard of accuracy the indicator must change colour in the narrow interval $\sim-4.16<\log \left[\mathrm{Me}^{\prime}\right]<\sim-4.0$.

This may be impossible to realize in practice.

An additional practical inconvenient of this titration is the slow decrease of [Me'] around the equivalence point which will cause a very gradual change in colour of the 
indicator and, by consequence, uncertainty and irreproducibility in locating the moment at which the titration has to be ended.

In any case, from Figure 5 we can judge that an indicator having $\beta_{1}^{\text {In, }}=10^{4}$ is too sensitive for this titration (as can be seen in the blink of an eye from the position of the horizontal line representing $-\log \beta_{1}{ }^{\text {In },}$ ).

On the contrary, Figure 6 presents titration curves for a titration performed with the same parameters as titrations in Figure 4 and Figure 5, except that $\beta_{1}{ }^{\prime}=10^{10}$ has been assumed.

This titration will give very easily accurate and reproducible results.

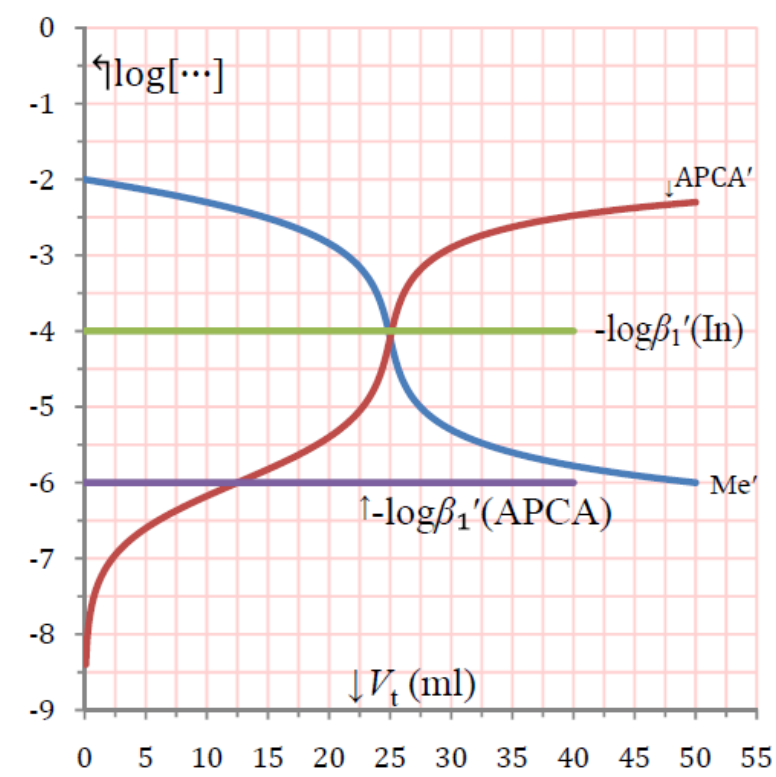

Figure 5. Complexometric titration curves $\log \left[\mathrm{Me} \mathrm{e}^{\prime}\right] V_{\mathrm{t}}(\mathrm{ml})$ and $\log \left[\right.$ APCA' $^{\prime} \rightarrow V_{\mathrm{t}}(\mathrm{ml})$ calculated with the following titration parameters: $C_{\mathrm{t}}^{\mathrm{M}}=0.0200 ; C_{0}^{\mathrm{M}}=0.0100 ; V_{0}^{\mathrm{ml}}=50.0 ; \beta_{1}{ }^{\prime}=10^{6}$. Furthermore, reference horizontal lines of ordinate $-\log \left(\beta_{1}{ }^{\text {In }}\right)=-4$ and $-\log \left(\beta_{1}{ }^{\prime}\right)=-6$ (whose significance is explained in the text) have been drawn

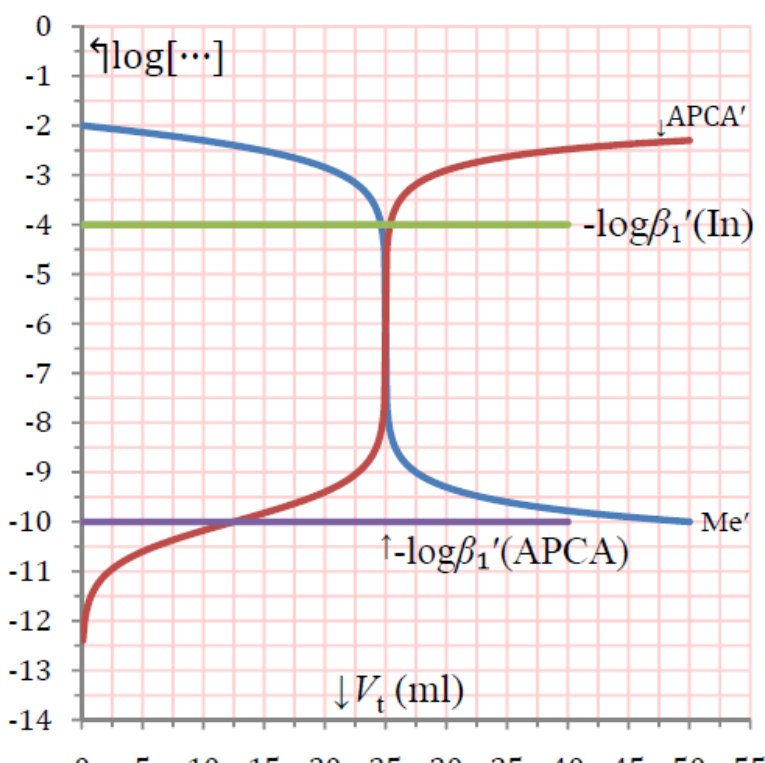

Figure 6. Complexometric titration curves $\log \left[\mathrm{Me}^{\prime}\right] \rightarrow V_{\mathrm{t}}(\mathrm{ml})$ and $\log \left[\right.$ APCA' $^{\prime} \rightarrow V_{\mathrm{t}}(\mathrm{ml})$ calculated with the following titration parameters: $C_{\mathrm{t}}^{\mathrm{M}}=0.0200 ; C_{0}^{\mathrm{M}}=0.0100 ; V_{0}^{\mathrm{ml}}=50.0 ; \beta_{1}{ }^{\prime}=10^{10}$. Reference horizontal lines of ordinate $-\log \left(\beta_{1}{ }^{\text {In }}{ }^{\prime}\right)=-4$ and $-\log \left(\beta_{1}{ }^{\prime}\right)=-10$ (whose significance is explained in the text) are also shown
By following the Me' curve in Figure 6, we see that at the equivalence point (at $V_{\mathrm{t}}=25.0 \mathrm{ml}$ ) $\log [\mathrm{Me}]_{\mathrm{eq}}=-6.1$. On the other side, from the plot we read $\log \left[\mathrm{Me}^{\prime}\right]_{-0.1}=-4.6$ and $\log \left[\mathrm{Me}^{\prime}\right]_{+0.1}=-7.6$. In order for this titration to meet our standard of accuracy, it is only necessary an indicator which changes colour in the wide interval $\sim-4.6<$ $\log \left[\mathrm{Me}^{\prime}\right]<\sim-7.6$.

It will be relatively easy to find an indicator which has, under the conditions of the titration, a conditional constant higher than about $10^{3.6}$ and lower than about $10^{6.6}$.

For instance, the indicator specified in Figure 6, which has $\beta_{1}{ }^{\text {In }}=10^{4}$, has a convenient sensitivity for this titration (as can be judged from the position of line with label $-\log \beta_{1}$ '(In)).

Furthermore, because of the rapid variation of [Me'] around the equivalence point, the change in colour will be very abrupt, making the location of the moment at which the titration has to be ended very simple and reproducible.

It can be noted at this point that most of the metal cations complexes with aminopolycarboxylic acids have absolute formation constants which largely exceed $10^{10}$.

However, most of the complexometric titrations in practical use are performed with conditional formation constants which generally are under about $10^{10}$, because of the drop of the conditional formation constants due to the side reactions, mainly of the amino polycarboxylate anion in acidic solutions and of the metal cation with auxiliary ligands which are introduced for a variety of reasons.

\subsection{Using MS Excel for Drawing Complexometric Titration Curves}

The data necessary to draw complexometric titration curves (like the ones presented above) for specified values of the titration parameters (i.e., $C_{\mathrm{t}}^{\mathrm{M}}, C_{0}^{\mathrm{M}}, V_{\mathrm{eq}}^{l}, \beta_{1}$ ' and $\beta_{1}{ }^{\text {In' }}$ ), can be generated in a matter of seconds after a MS Excel sheet, which we shall call $<$ ArrayGenerator $>$ has been developed.

Data produced by <ArrayGenerator $>$ are then copied and pasted as values to a second empty MS Excel sheet which we shall call $<$ MyTitrationMatrix $>$.

$<$ MyTitrationMatrix $>$ sheet exposes a matrix of numbers with four column and 502 rows. Each row (except the first row used for labels indicating the contents of each column) is an array with four elements (corresponding, respectively, to values of $V_{\mathrm{t}}(\mathrm{ml}), \log [\mathrm{Me}]$, $\log \left[\mathrm{APCA}^{\prime}\right]$ and $\left.\log [\mathrm{MeAPCA}]\right)$ that represents one point of the titration. In $<$ MyTitrationMatrix $>$ MS Excel sheet, plots exposing $\quad \log \left[\mathrm{Me}^{\prime}\right] \rightarrow V_{\mathrm{t}}(\mathrm{ml})$, $\log \left[\right.$ APCA' $^{\prime} \rightarrow V_{\mathrm{t}}(\mathrm{ml}) \quad$ and, eventually, $\log [$ MeAPCA' $] \rightarrow V_{\mathrm{t}}(\mathrm{ml})$ curves are immediately drawn using standard MS Excel menus.

In order to develop the <ArrayGenerator $>$ sheet in a short time, consider Figure 7 which represents the first 12 rows of the corresponding MS Excel sheet.

Cells with a pale yellow background contain labels while cells with dashed background are left empty.

As a first step enter the following labels, $\langle\cdots\rangle$, in the indicated cells of $<$ ArrayGenerator $>$ sheet:
$<$ Burette $\rightarrow \mathrm{Vt}(\mathrm{ml})>$
$<\mathrm{C}_{\text {APCA }}(\mathrm{M})>$
$<C_{\mathrm{Me}}(\mathrm{M})>$
cell A1;
$<1+\beta_{1}{ }^{\prime} \cdot \mathrm{C}_{\mathrm{APCA}}-\beta_{1}{ }^{\prime} \cdot \mathrm{C}_{\mathrm{Me}}>$
cell B1;
cell C1;
cell D1; 
$<\log \left[\mathrm{Me}^{\prime}\right]>$

$<\log \left[\right.$ APCA'] $^{\prime}>$

$<\log [\mathrm{MeAPCA}]>$

$<C_{\mathrm{t}}(\mathrm{M}) \rightarrow>$

$<C_{0}(\mathrm{M}) \rightarrow>$

$<V_{0}(\mathrm{ml}) \rightarrow>$

$<\beta_{1}^{\prime}$ (APCA) $\rightarrow>$

After this, enter default values for the titration parameters.

In cell J2 enter the default value for the molar concentration of the standard aminopolycarboxylic acid solution (i.e., 0.02); in cell J3 enter the default value for the molar concentration of the metal cation in the titrated solution (i.e., 0.010); in cell J4 enter the default value for the volume in $\mathrm{ml}$ of the titrated solution (i.e., 50.00); finally in cell $\mathrm{J} 5$ enter the default value for the $\beta_{1}$ (APCA) (i.e., $10^{8}$ ).

Column A of the <ArrayGenerator $>$ sheet is labelled $<$ Burette $\rightarrow V_{\mathrm{t}}(\mathrm{ml})>$ and must be intended as representing the burette which delivers the titrant solution. As a real burette, it can deliver up to $50 \mathrm{ml}$ of titrant and it is graduated each $0.1 \mathrm{ml}$. Then, using standard Excel tools, generate, in cells from A2 to A502, $501 V_{\mathrm{t}}(\mathrm{ml})$ values from zero up to 50 spaced 0.1 (see Figure 7).

In cells indicated in the following Table 3, enter the corresponding code (you can copy the code and paste it in the appropriate cell). After this, extend with the usual Excel tools, the code in cells B2, C2, D2, E2, F3 and G3 up to cells B502, C502, D502, E502, F502 and G502.

This will fill columns of the <ArrayGenerator $>$ sheet with numbers whose significance is specified in the label identifying each column.

Finally, cells are formatted as shown in Figure 7. Naturally, the default titration parameters, in cells J2, J3, $\mathrm{J} 4$ and $\mathrm{J} 5$, are modified to simulate any planned titration; the contents of the <ArrayGenerator> sheet are automatically updated on changing the titration parameters.

\begin{tabular}{|c|c|c|c|c|c|c|c|c|c|c|}
\hline 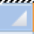 & A & B & c & D & $\mathrm{E}$ & $\mathrm{F}$ & G & $\mathrm{H}$ & 1 & j \\
\hline 1 & Burette $\rightarrow V_{t}(\mathrm{ml})$ & $C_{\mathrm{APCA}}(\mathrm{M})$ & $C_{\mathrm{Me}}(\mathrm{M})$ & $1+\beta_{1}^{\prime} \cdot \mathrm{C}_{\mathrm{APCA}}-\beta_{1}^{\prime} \cdot C_{\mathrm{Me}}$ & $\log \left[\mathrm{Me}^{\prime}\right]$ & $\log \left[\mathrm{APCA}^{\prime}\right]$ & $\log [\mathrm{MeAPCA}]$ & & mink & al \\
\hline 2 & 0.00 & $0.000 \mathrm{E}+00$ & $1.000 \mathrm{E}-02$ & $-1.000 E+06$ & -2.000 & & & & $C_{\mathrm{t}}(\mathrm{M}) \rightarrow$ & 0.02000 \\
\hline 3 & 0.10 & $3.992 \mathrm{E}-05$ & $9.980 \mathrm{E}-03$ & $-9.940 \mathrm{E}+05$ & -2.003 & -10.396 & -4.399 & & $C_{0}(\mathrm{M}) \rightarrow$ & 0.01000 \\
\hline 4 & 0.20 & $7.968 \mathrm{E}-05$ & $9.960 \mathrm{E}-03$ & $-9.880 \mathrm{E}+05$ & -2.005 & -10.093 & -4.099 & & $V_{0}($ litre $) \rightarrow$ & 50.000 \\
\hline 5 & 0.30 & $1.193 \mathrm{E}-04$ & $9.940 \mathrm{E}-03$ & $-9.821 \mathrm{E}+05$ & -2.008 & -9.916 & -3.923 & & $\beta_{1}^{\prime}(\mathrm{APCA}) \rightarrow$ & $1.000 \mathrm{E}+08$ \\
\hline 6 & 0.40 & $1.587 \mathrm{E}-04$ & $9.921 \mathrm{E}-03$ & $-9.762 E+05$ & -2.010 & -9.789 & -3.799 & & & \\
\hline 7 & 0.50 & $1.980 \mathrm{E}-04$ & $9.901 \mathrm{E}-03$ & $-9.703 E+05$ & -2.013 & -9.690 & -3.703 & & & \\
\hline 8 & 0.60 & $2.372 \mathrm{E}-04$ & $9.881 \mathrm{E}-03$ & $-9.644 \mathrm{E}+05$ & -2.016 & -9.609 & -3.625 & & & \\
\hline 9 & 0.70 & $2.761 \mathrm{E}-04$ & $9.862 \mathrm{E}-03$ & $-9.586 \mathrm{E}+05$ & -2.018 & -9.541 & -3.559 & & & \\
\hline 10 & 0.80 & $3.150 \mathrm{E}-04$ & $9.843 \mathrm{E}-03$ & $-9.528 \mathrm{E}+05$ & -2.021 & -9.481 & -3.502 & & & \\
\hline 11 & 0.90 & $3.536 \mathrm{E}-04$ & $9.823 \mathrm{E}-03$ & $-9.470 \mathrm{E}+05$ & -2.024 & -9.428 & -3.451 & & & \\
\hline 12 & 1.00 & $3.922 \mathrm{E}-04$ & $9.804 \mathrm{E}-03$ & $-9.412 \mathrm{E}+05$ & -2.026 & -9.380 & -3.407 & & & \\
\hline
\end{tabular}

Figure 7. First twelve rows (out of 502 rows) of <ArrayGenerator $>$ MS Excel sheet

Table 3. Code to be entered in MS Excel <ArrayGenerator> sheet

\begin{tabular}{|c|c|}
\hline Cell & Code \\
\hline $\mathrm{B} 2$ & $=\$ \mathrm{~J} \$ 2 * \mathrm{~A} 2 /(\mathrm{A} 2+\$ \mathrm{~J} \$ 4)$ \\
\hline $\mathrm{C} 2$ & $=\$ \mathrm{~J} \$ 3 * \$ \mathrm{~J} \$ 4 /(\mathrm{A} 2+\$ \mathrm{~J} \$ 4)$ \\
\hline $\mathrm{D} 2$ & $=1+\mathrm{B} 2 * \$ \mathrm{~J} \$ 5-\mathrm{C} 2 * \$ \mathrm{~J} \$ 5$ \\
\hline $\mathrm{E} 2$ & $=\mathrm{LOG} 10\left(\left(-\mathrm{D} 2+\left(\mathrm{D} 2 \wedge 2+4 * \$ \mathrm{~J} \$ 5^{*} \mathrm{C} 2\right)^{\wedge} 0.5\right) /(2 * \$ \mathrm{JS} 5)\right)$ \\
\hline F3 & $=\mathrm{LOG} 10\left(\mathrm{~B} 3 /\left(1+\$ \mathrm{~J} \$ 5^{*} 10^{\wedge} \mathrm{E} 3\right)\right)$ \\
\hline G3 & $=\mathrm{LOG} 10(\$ \mathrm{~J} \$ 5)+\mathrm{E} 3+\mathrm{F} 3$ \\
\hline
\end{tabular}

Suppose now that you want to verify the performance of the well established direct titration of $\mathrm{Zn}^{2+}$ with a standard $0.0200 \mathrm{M}$ EDTA solution, in an ammoniacal environment, in presence of Eriochrome Black T (EBT) as an indicator $[4,6]$. Consequently, according to the standard procedure, take, in abstract, $100 \mathrm{ml}$ of a solution of a $\mathrm{Zn}^{2+}$ salt containing an initial zinc concentration of $0.005 \mathrm{M}$ and add a few $\mathrm{ml}$ (say $5 \mathrm{ml}$ ) of the very popular $\mathrm{NH}_{3} / \mathrm{NH}_{4}{ }^{+}$ buffer of $\mathrm{pH} \approx 10$ (this buffer is a concentrated solution which contains about $10 \mathrm{M} \mathrm{NH}_{3}$ and $1.3 \mathrm{M} \mathrm{NH} \mathrm{NH}_{4} \mathrm{Cl}$ ). Suppose that these operations produce $105 \mathrm{ml}$ of a solution which contains $0.0048 \mathrm{M} \mathrm{Zn}^{2+}+0.48 \mathrm{M} \mathrm{NH}_{3}+$ $0.062 \mathrm{M} \mathrm{NH}_{4} \mathrm{Cl}$ and has a $\mathrm{pH} \approx 10.2$ (calculated from the ratio $\left[\mathrm{NH}_{3} /\left[\mathrm{NH}_{4}^{+}\right]\right.$and the Henderson-Hasselbalch equation).

Thus, enter 0.02 in cell J2, 0.0048 in cell J3 and 105 in cell J4 of $<$ ArrayGenerator $>$.

In cell $\mathrm{J} 5$ of $<$ ArrayGenerator $>$ enter the value of the conditional equilibrium constant for reaction between groups Zn' + EDTA' $\rightleftharpoons$ ZnEDTA'. From the list of reactions in Table 1 and expressions for the alfa coefficients in Table 2 we evaluate $\beta_{1}{ }^{\prime}=3.45 \cdot 10^{8}$ (numerical details of this calculation can be seen in Table 4).

After this, select and copy columns A, E, F and G of $<$ ArrayGenerator $>$ and paste them as values in an empty $<$ MyTitrationMatrix $>$ sheet.

It is useful to update labels in row 1, by substituting [Zn'], [EDTA'] and [ZnEDTA'] in place of the generic labels [Me'], [APCA'] and [MeAPCA'].

Finally, select columns A, B and C of $<$ MyTitrationMatrix $>$ and insert a line graph, with the standard Excel procedure.

Optionally, using standard Excel tools, one can add to the plot lines corresponding to $-\log \left(\beta_{1}{ }^{\prime}(\right.$ EDTA $\left.)\right)=-8.5$ and $-\log \left(\beta_{1}{ }^{\prime}(\mathrm{EBT})\right)=-3.8$ (see below).

After formatting, the plot should appear like the one in Figure 8.

From Figure 8 one can see an equivalence point at $25.20 \mathrm{ml}$ which is reached when the [Me'] group concentration is $10^{-5.48}$ (actually, these values are read from $<$ MyTitrationMatrix $>$ sheet).

In order to keep the difference $\left|V_{\text {eq }}-V_{\text {arr }}\right| \leqq 0.1 \mathrm{ml}$, an indicator is required which changes colour in the interval $4.8<\log \left[\mathrm{Me}^{\prime}\right]<-6.2$ (these values can be read in $<$ MyTitrationMatrix $>$ sheet in correspondence of $V_{\mathrm{t}}=25.1$ $\mathrm{ml}$ and $25.3 \mathrm{ml}$, respectively).

Is Eriochrome Black T (see §1) such an indicator?

In order to answer the above question we need to calculate the conditional constant for reaction between groups of species Zn' + EBT' $\rightleftharpoons$ ZnEBT'. 
This is easily done on the basis of the list of reactions in Table 1 and relations in Table 2 (see Table 4 for details). We calculate $\beta_{1}{ }^{\prime}(\mathrm{EBT})=5.9 \cdot 10^{3}$.

Table 4. Calculation of the alfa coefficients and conditional formation constants for the system $\mathrm{Zn}^{2+} / \mathrm{EDTA} / \mathrm{EBT}$ in an ammoniacal buffer of $\mathrm{pH}=10.2$ and $\left[\mathrm{NH}_{3}\right]=0.48 \mathrm{M}$

\begin{tabular}{|c|}
\hline $\begin{array}{l}\alpha_{\mathrm{Zn}}=\beta_{1}^{\mathrm{OH}}\left[\mathrm{OH}^{-}\right]+\beta_{2}^{\mathrm{OH}}\left[\mathrm{OH}^{-}\right]^{2}+\beta_{3}^{\mathrm{OH}}\left[\mathrm{OH}^{-}\right]^{3} \\
+\beta_{4}^{\mathrm{OH}}\left[\mathrm{OH}^{-}\right]^{4}+\beta_{1}^{\mathrm{NH}_{3}}\left[\mathrm{NH}_{3}\right]+\beta_{2}^{\mathrm{NH}_{3}}\left[\mathrm{NH}_{3}\right]^{2} \\
+\beta_{3}^{\mathrm{NH}_{3}}\left[\mathrm{NH}_{3}\right]^{3}+\beta_{4}^{\mathrm{NH}_{3}}\left[\mathrm{NH}_{3}\right]^{4} \\
=10^{5.00} 10^{-3.8}+10^{11.11}\left(10^{-3.8}\right)^{2}+10^{13.61}\left(10^{-3.8}\right)^{3} \\
+10^{14.81}\left(10^{-3.8}\right)^{4}+10^{2.21}(0.48)+10^{4.5}(0.48)^{2} \\
+10^{6.86}(0.48)^{3}+10^{8.89}(0.48)^{4}=4.2 \times 10^{7}\end{array}$ \\
\hline $\begin{array}{l}\alpha_{\text {EDTA }}=1+\beta_{1}^{\text {EDTA }}\left[H^{+}\right]+\beta_{2}^{\text {EDTA }}\left[H^{+}\right]^{2} \\
+\beta_{3}^{\text {EDTA }}\left[H^{+}\right]^{3}+\beta_{4}^{\text {EDTA }}\left[H^{+}\right]^{4} \\
=1+10^{10.17} 10^{-10.2}+10^{16.28}\left(10^{-10.2}\right)^{2} \\
+10^{18.96}\left(10^{-10.2}\right)^{3}+10^{20.96}\left(10^{-10.2}\right)^{4}=1.9\end{array}$ \\
\hline $\begin{array}{l}\alpha_{\text {ZnEDTA }}=1+\beta_{\mathrm{H}}^{\mathrm{ZnEDTA}}\left[\mathrm{H}^{+}\right]+\beta_{\mathrm{OH}}^{\mathrm{ZnEDTA}}\left[\mathrm{OH}^{-}\right] \\
=1+10^{3.0} 10^{-10.2}+10^{2.1} 10^{-3.8}=1\end{array}$ \\
\hline$\beta_{1}^{\prime}=\beta_{1} \frac{\alpha_{\text {ZnEDTA }}}{\alpha_{Z n} \times \alpha_{E D T A}}=10^{16.44} \frac{1}{4.2 \cdot 10^{7} \times 1.9}=3.45 \cdot 10^{8}$ \\
\hline $\begin{array}{l}\alpha_{\text {EBT }}=1+\beta_{1}^{\text {EBT }}\left[H^{+}\right]+\beta_{2}^{\text {EBT }}\left[H^{+}\right]^{2} \\
=1+10^{11.39} 10^{-10.2}+10^{18.3}\left(10^{-10.2}\right)^{2}=16.5\end{array}$ \\
\hline
\end{tabular}

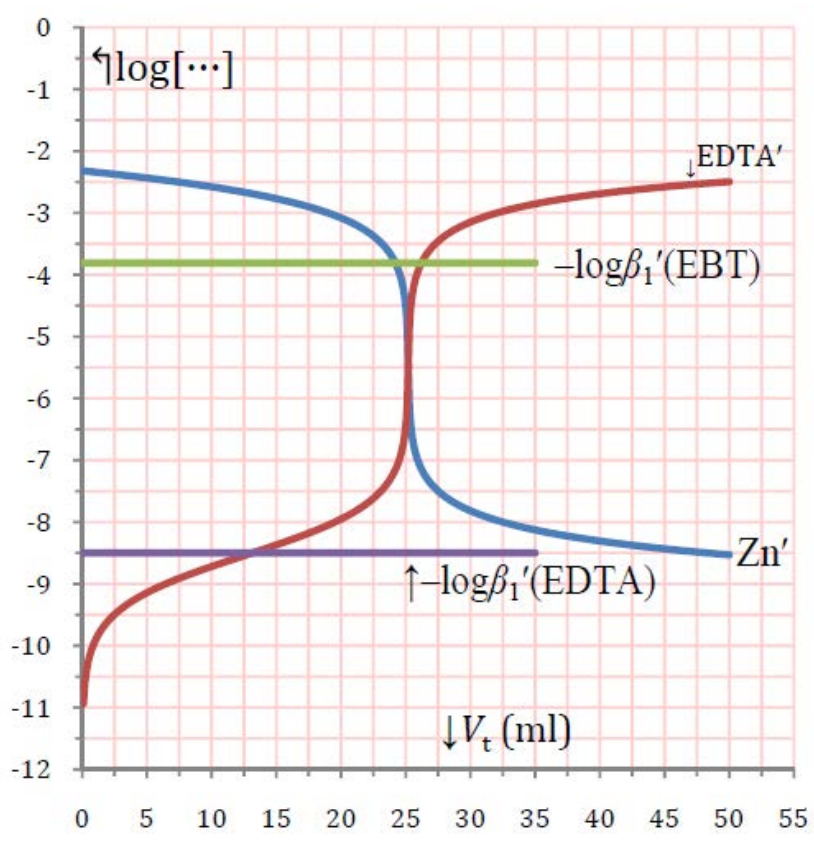

Figure 8. Graphical presentation of the titration of $105 \mathrm{ml}$ of a $0.0048 \mathrm{M}$ $\mathrm{Zn}^{2+}$ with standard 0.02 M EDTA in an ammoniacal solution $(0.48 \mathrm{M}$ $\left.\mathrm{NH}_{3}+0.062 \mathrm{M} \mathrm{NH}_{4} \mathrm{Cl} ; \mathrm{pH} \approx 10.2\right)$ in presence of Eriochrome Black T as indicator. Reference horizontal lines of ordinate $-\log \beta_{1}{ }^{\prime}(\mathrm{EBT})=-3.8$ and $-\log \beta_{1}{ }^{\prime}($ EDTA $)=-8.5$ are also shown

From this value we deduce that equal concentrations of the red ZnEBT' complex and the blue EBT' indicator are present when, during the titration, $\log [\mathrm{Zn}$ '] has dropped to -3.8 (= $-\log \left(\beta_{1}\right.$ '(EBT)). The pure blue colour of EBT' will appear somewhat further during the titration when $\log [\mathrm{Zn}$ '] has fallen to about $-4.8\left(=-\log \left(\beta_{1}{ }^{\prime}(\mathrm{EBT})\right)-1\right)$.

From this, it is clear that the titration will be stopped somewhat before the equivalence point (i.e., EBT sensitivity is a little low for this titration) but in any case the difference $\left|V_{\text {eq }}-V_{\text {arr }}\right|$ does not exceed $\sim 0.1 \mathrm{ml}$ (which is the set standard of accuracy).

The horizontal line in Figure 8, representing the transition point of the indicator $\left(\log [\mathrm{Zn}]=-\log \left(\beta_{1}\right.\right.$ '(EBT)) helps to understand the above considerations.

\subsection{The Special Meaning of the Complexometric Titration of $\mathbf{M g}^{2+}$ Cation with EDTA}

Table 5 presents a list of reactions and of the corresponding equilibrium constants which will be the basis of discussion in this paragraph.

The complexometric titration of magnesium with EDTA in presence of Eriochrome Black T as indicator is obviously based on the reactions between groups:

$$
\begin{gathered}
\mathrm{Mg}{ }^{\prime}+\mathrm{EDTA}^{\prime} \rightleftharpoons \mathrm{MgEDTA}^{\prime} \rightarrow \beta_{1}{ }^{\prime}\left(\mathrm{EDTA}^{\mathrm{Mg}}\right) \\
\mathrm{Mg}^{\prime}+\mathrm{EBT}^{\prime} \rightleftharpoons \mathrm{MgEBT}^{\prime} \rightarrow \beta_{1}{ }^{\prime}\left(\mathrm{EBT}^{\mathrm{Mg}}\right)
\end{gathered}
$$

Table 5. Primary and side reactions of $\mathrm{Mg}^{2+}$ and $\mathrm{Ca}^{2+}$ cations to be considered for evaluating their titration with EDTA in an

\begin{tabular}{|c|c|c|}
\hline 1 & 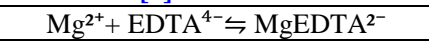 & $\log \beta=8.830$ \\
\hline 2 & $\mathrm{Mg}^{2^{+}}+\mathrm{EBT}^{3^{-}} \leftrightharpoons \mathrm{Mg}^{2+} \mathrm{EBT}^{-}$ & $\log \beta=7.000$ \\
\hline 3 & $\mathrm{Mg}^{2^{+}}+\mathrm{OH}^{-} \leftrightharpoons \mathrm{MgOH}^{+}$ & $\log \beta=2.583$ \\
\hline 4 & $\mathrm{Mg}^{2^{+}}+\mathrm{NH}_{3} \leftrightharpoons \mathrm{Mg} \mathrm{NH}^{2+}$ & $\log \beta=0.230$ \\
\hline 5 & $\mathrm{Mg}^{2^{+}}+2 \mathrm{NH}_{3} \leftrightharpoons \mathrm{Mg}\left(\mathrm{NH}_{3}\right)_{2} 2^{2^{+}}$ & $\log \beta=0.080$ \\
\hline 6 & $\mathrm{Mg}^{2+}+3 \mathrm{NH}_{3} \leftrightharpoons \mathrm{Mg}\left(\mathrm{NH}_{3}\right)_{3}{ }^{2^{+}}$ & $\log \beta=-0.300$ \\
\hline 7 & $\mathrm{Mg}^{2+}+\mathrm{H}^{+}+\mathrm{EDTA}^{4-} \leftrightharpoons \mathrm{MgHEDTA}^{-}$ & $\log \beta=3.85$ \\
\hline 8 & 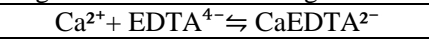 & $\log \beta=10.610$ \\
\hline 9 & $\mathrm{Ca}^{2+}+\mathrm{EBT}^{3^{-}} \leftrightharpoons \mathrm{CaEBT}^{-}$ & $\log \beta=5.400$ \\
\hline 10 & $\mathrm{Ca}^{2+}+\mathrm{OH}^{-} \leftrightharpoons \mathrm{CaOH}^{+}$ & $\log \beta=1.303$ \\
\hline 11 & $\mathrm{Ca}^{2+}+\mathrm{NH}_{3} \leftrightharpoons \mathrm{CaNH}_{3}{ }^{2+}$ & $\log \beta=-0.200$ \\
\hline 12 & $\mathrm{Ca}^{2^{+}}+2 \mathrm{NH}_{3} \leftrightharpoons \mathrm{Ca}\left(\mathrm{NH}_{3}\right)_{2}{ }^{2^{+}}$ & $\log \beta=-0.800$ \\
\hline 13 & $\mathrm{Ca}^{2+}+3 \mathrm{NH}_{3} \leftrightharpoons \mathrm{Ca}\left(\mathrm{NH}_{3}\right)_{3}{ }^{2^{+}}$ & $\log \beta=-0.300$ \\
\hline 14 & $\mathrm{NH}_{3}+\mathrm{H}^{+} \leftrightharpoons \mathrm{NH}_{4}^{+}$ & $\log \beta=9.290$ \\
\hline 15 & $\mathrm{EDTA}^{4-}+\mathrm{H}^{+} \leftrightharpoons \mathrm{HEDTA}^{3^{-}}$ & $\log \beta=10.170$ \\
\hline 16 & $\mathrm{EDTA}^{4-}+2 \mathrm{H}^{+} \leftrightharpoons \mathrm{H}_{2} \mathrm{EDTA}^{2-}$ & $\log \beta=16.280$ \\
\hline 17 & $\mathrm{EDTA}^{4-}+3 \mathrm{H}^{+} \leftrightharpoons \mathrm{H}_{3} \mathrm{EDTA}^{-}$ & $\log \beta=18.960$ \\
\hline 18 & $\mathrm{EDTA}^{4-}+4 \mathrm{H}^{+} \leftrightharpoons \mathrm{H}_{4} \mathrm{EDTA}$ & $\log \beta=20.960$ \\
\hline 19 & $\mathrm{EBT}^{3^{-}}+\mathrm{H}^{+} \leftrightharpoons \mathrm{HEBT}^{2-}$ & $\log \beta=11.390$ \\
\hline 20 & $\mathrm{EBT}^{3^{-}}+2 \mathrm{H}^{+} \leftrightharpoons \mathrm{H}_{2} \mathrm{EBT}^{-}$ & $\log \beta=18.290$ \\
\hline
\end{tabular}
ammoniacal buffer [7]

Supposing that the sample contains several $\mathrm{mg} / \mathrm{l}$ of magnesium, a $100 \mathrm{ml}$ volume is transferred to a titration flask and, according to a standard procedure [4,6], buffered by adding $10 \mathrm{ml}$ of the $\mathrm{pH} \approx 10$ ammoniacal buffer $\left(10 \mathrm{M} \mathrm{NH}_{3}+1.3 \mathrm{M} \mathrm{NH} \mathrm{NH}_{4} \mathrm{Cl}\right)$. Then sufficient Eriochrome Back T indicator powder is added to obtain a clearly visible red colour. Finally, the solution is titrated with standard EDTA solution until a pure blue colour appears.

A representative case of this titration is presented in Figure 9.

As can be seen from Figure 9, under the described conditions, $\beta_{1}{ }^{\prime}\left(\mathrm{EDTA}^{\mathrm{Mg}}\right)=8.3 \cdot 10^{7}$ and $\beta_{1}{ }^{\prime}\left(\mathrm{EBT}^{\mathrm{Mg}}\right)=$ $1.4 \cdot 10^{5}$ are calculated from relations in Table 2 and reactions in Table 5 . 


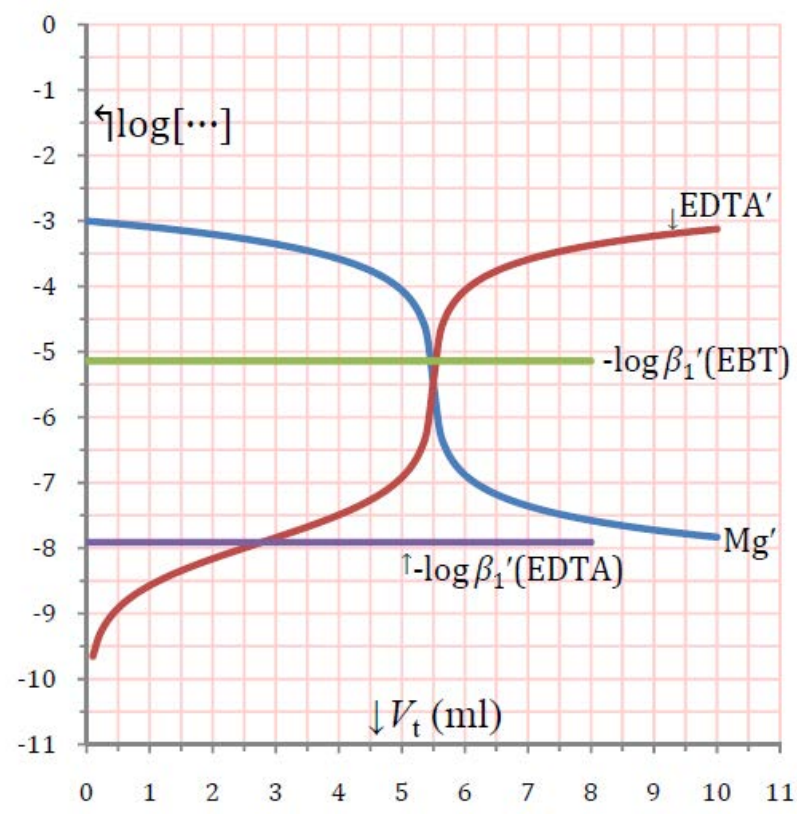

Figure 9. Graphical presentation of the titration of $110 \mathrm{ml}$ of $0.001 \mathrm{M}$ $\mathrm{Mg}^{2+}$ with standard $0.02 \mathrm{M}$ EDTA in an ammoniacal solution $(0.91 \mathrm{M}$ $\mathrm{NH}_{3}+0.012 \mathrm{M} \mathrm{NH}_{4} \mathrm{Cl} ; \mathrm{pH} \approx 10.2$ ) in presence of Eriochrome Black T as indicator. Reference horizontal lines of ordinate $-\log \beta_{1}{ }^{\prime}\left(\mathrm{EBT}^{\mathrm{Mg}}\right)=-5.14$ and $-\log \beta_{1}{ }^{\prime}\left(\mathrm{EDTA}^{\mathrm{Mg}}\right)=-7.91$ are also shown

Figure 9 is readily generated using <ArrayGenerator $>$ MS Excel sheet, the given values of the conditional constants and other titrations data given in the legend of the figure.

The equivalence point of this titration is $V_{\text {eq }}=5.50 \mathrm{ml}$ and $\log \left[\mathrm{Mg}^{\prime}\right]_{\mathrm{eq}}=-5.47$ (as can be read from $<$ MyTitrationMatrix $>$ Excel sheet for this titration). Furthermore, we have: $\log \left[\mathrm{Mg}^{\prime}\right]_{-0.1}=-4.74$ and $\log \left[\mathrm{Mg}^{\prime}\right]_{+0.1}=-6.2$.

The full blue colour of the free Eriochrome Black $\mathrm{T}$ indicator is predicted to develop somewhat after the equivalence point (i.e., the sensitivity of Eriochrome Black $\mathrm{T}$ for magnesium is somewhat higher than required) at $\log \left[\mathrm{Mg}^{\prime}\right] \approx\left(\log \left(\beta_{1}{ }^{\prime}(\mathrm{EBT})\right)-1\right)=-6.14$. However, the titration is stopped within the interval $-6.2<\log \left[\mathrm{Mg}^{\prime}\right]<-$ 4.74 , which is necessary to keep the absolute accuracy within $\pm 0.1 \mathrm{ml}$.

Calcium $^{2+}$ ion is the most common interferent in the determination of magnesium. In fact, the presence of calcium during the determination of magnesium, under the conditions described above, introduces two additional reactions between groups. From data in Table 5 and relations in Table 2, we have:

$$
\begin{aligned}
& C a^{\prime}+E D T A^{\prime} \rightleftharpoons C a E D T A^{\prime} \\
& \rightarrow \beta_{1}{ }^{\prime}\left(E D T A^{C a}\right)=1.0 \cdot 10^{10} \\
& C a^{\prime}+E B T^{\prime} \rightleftharpoons C a E B T^{\prime} \\
& \rightarrow \beta_{1}{ }^{\prime}\left(E B T^{C a}\right)=6.8 \cdot 10^{3}
\end{aligned}
$$

Figure 10 represents the complexometric titration of magnesium under the same conditions of Figure 9, except that an equal concentration of calcium has been supposed to be present in the titrated solution.

As can be seen, curve representing $\log [\mathrm{Ca}$ '] and line representing - $\log \beta_{1}{ }^{\prime}\left(\mathrm{EBT}^{\mathrm{Ca}}\right)$ have been added.

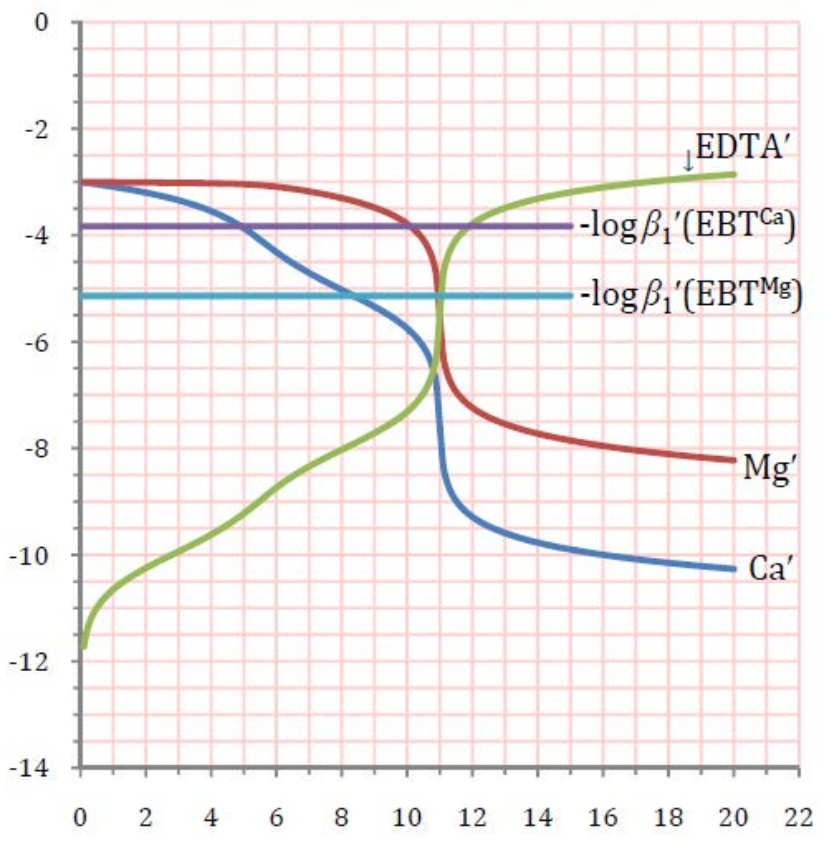

Figure 10. Graphical presentation of the titration of $110 \mathrm{ml}$ of $0.001 \mathrm{M}$ $\mathrm{Mg}^{2+}+0.001 \mathrm{M} \mathrm{Ca}^{2+}$, with standard $0.02 \mathrm{M}$ EDTA in an ammoniacal solution $\left(0.91 \mathrm{M} \mathrm{NH}_{3}+0.012 \mathrm{M} \mathrm{NH}_{4} \mathrm{Cl} ; \mathrm{pH} \approx 10.2\right)$ in presence of Eriochrome Black $\mathrm{T}$ as indicator. Reference horizontal lines of ordinate $\log \beta_{1}{ }^{\prime}\left(\mathrm{EBT}^{\mathrm{Ca}}\right)=-3.83$ and $-\log \beta_{1}{ }^{\prime}\left(\mathrm{EBT}^{\mathrm{Mg}}\right)=-5.14$ are also shown. Simulation has been performed with MS Windows Forms application attached to [9]

The red colour of the solution at the beginning of this titration is essentially due to the complexes of the group MgEBT'. This can be seen at the blink of an eye from Figure 10, since line representing $-\log \beta_{1}{ }^{\prime}\left(\mathrm{EBT}^{\mathrm{Mg}}\right)$ lies much under line representing $-\log \beta_{1}{ }^{\prime}\left(\mathrm{EBT}^{\mathrm{Ca}}\right.$ ) (which implies that MgEBT' is much more stable than CaEBT'). As a consequence, in order for the indicator to change colour, MgEBT' must be decomposed. As in Figure 9, this will happen when $\log \left[\mathrm{Mg}^{\prime}\right] \approx\left(-\log \left(\beta_{1}{ }^{\prime}\left(\mathrm{EBT}^{\mathrm{Mg}}\right)\right)-1\right)=-$ 6.14 .

The volume of $0.02 \mathrm{M}$ EDTA standard solution consumed, that, in abstract, we read on the burette when $\log \left[\mathrm{Mg}^{\prime}\right] \approx-6.14$ is calculated to be $V_{\text {arr }}=11.08 \mathrm{ml}$.

Evidently, this volume is, to a very good approximation, twice the volume we would have determined if only magnesium was present. This is because an equal volume of EDTA is consumed to produce the complex CaEDTA' from Ca', whose concentration, when the indicator changes colour, has dropped to very low value $\left(\lesssim 10^{-8.2} \mathrm{M}\right.$ as judged from Figure 10).

It is easy to see that the product $C_{\mathrm{t}}^{\mathrm{M}} \cdot V_{\text {arr }}^{l} \quad$ (= $0.02 \cdot 0.01108=2.21 \cdot 10^{-4}$ moles) does not correspond to the number of moles of magnesium but, within the accuracy of the titration, it represents the sum of the number of moles of calcium and magnesium.

Because of this, in general, the determination of magnesium, according to the above procedure, is best interpreted on the basis of relation (57):]

$$
C_{\mathrm{t}}^{\mathrm{M}} \cdot V_{\mathrm{arr}}^{l}=\text { moles } \rightarrow \mathrm{Mg}^{2+}+\text { moles } \rightarrow \mathrm{Ca}^{2+}
$$

Only in the case one can assure that no calcium is present in the titrated solution, relation (57) will give the amount of magnesium in the titrated solution.

It must be understood that titrations presented in Figure 9 and Figure 10, although they may appear at first sight 
very different from each other, are practically indistinguishable, that is they appear to perform exactly in the same way.

This is a demonstration of the fact that titrations with aminopolycarboxylic acids hardly, if ever, allow the determination of a single metal cation in presence of others, (that is, complexometric titrations with aminopolycarboxylic acids are not selective).

Although this lack of selectivity is in general considered as a limitation of the technique, it is, nonetheless, useful from a practical point of view.

In fact, for instance, total water hardness is obtained essentially by performing the above titration on a water sample.

From equation (57) one gets the idea that if magnesium is absent from the titrated solution, the above titration would allow the determination of calcium.

In abstract this is true, although the sensitivity of Eriochrome Black T for calcium is somewhat low.

However, in practice, calcium cannot be determined by the above titration procedure because of the slowness of the reaction CaEBT' + EDTA' $\rightleftharpoons$ CaEDTA' + EBT' which is responsible for the change of colour of the titrated solution.

In fact, if magnesium is absent, the initial red colour of the solution is obviously due to the complex CaEBT' and (as a consequence of the slow decomposition of CaEBT' by EDTA') the solution will turn blue very slowly. Since visual titrations are performed by continually adding the titrant until the colour change is observed, it is easy to see that when the blue colour finally slowly appears in the solution and the titration is stopped, the volume that we read on the burette is, presumably, much larger than the equivalence volume.

This is what it is meant when we say that $\mathrm{Ca}^{2+}$ blocks Eriochrome Black T. Then, another indicator must be used for the complexometric titration of calcium.

However, there are a number of intriguing ways in which this obstacle can be overcome.

The most used chemical device for determining calcium using exactly the same conditions described above for the determination of magnesium, rests on the fact that the MgEDTA $^{2-}$ complex can be prepared in a pure solid form as a sodium salt (i.e., $\mathrm{Na}_{2} \mathrm{Mg}(\mathrm{EDTA})$ ).

By adding to the calcium solution a controlled amount of the $\mathrm{Na}_{2} \mathrm{Mg}$ (EDTA) salt, the titration of calcium will change into the titration of magnesium without altering the volume of EDTA consumed in the titration. This is because the reaction MgEDTA' + Ca' $\rightleftharpoons$ CaEDTA' + Mg' takes place with a very high yield under the described conditions, since the CaEDTA' complex $\left(\beta_{1}{ }^{\prime}\left(\mathrm{EDTA}^{\mathrm{Ca}}\right)=\right.$ $\left.1.0 \cdot 10^{10}\right)$ is much more stable than the corresponding MgEDTA' complex $\left(\beta_{1}{ }^{\prime}\left(\right.\right.$ EDTA $\left.\left.^{\mathrm{Mg}}\right)=8 \cdot 3 \cdot 10^{7}\right)$.

This type of titration is usually called a replacement titration.

As a matter of fact, for many metal cations, replacement reactions of the type MgEDTA' $+\mathrm{Me}^{\prime} \rightleftharpoons$ MeEDTA' + Mg' proceed with an high yield, so that the complexometric titration of a variety of metals can be reduced to the determination of magnesium (i.e., $\mathrm{Mg}^{2+}$ can be substituted and titrated in place of the target $\mathrm{Me}^{\mathrm{z}^{+}}$ cation).

Even more intriguing is the fact that the titration of magnesium with EDTA in presence of EBT can be inverted (that is, EDTA can be titrated with a standard solution of $\mathrm{Mg}^{2+}$, still using EBT as an indicator). This inverted titration is usually called a back-titration.

Figure 11 gives an example of the back-titration of an EDTA solution with a standard $0.02 \mathrm{M}$ solution of $\mathrm{MgSO}_{4}$. It is supposed that the back-titration is performed under the same conditions as the direct titration (i.e., the EDTA solution is buffered with about $1 \mathrm{ml}$ of $\mathrm{pH} \approx 10$ ammoniacal buffer each $10 \mathrm{ml}$ of titrated solution), so that the reactions between groups and the corresponding conditional constants are exactly the same as during the direct titration (as can be judged confronting Figure 11 with Figure 9).

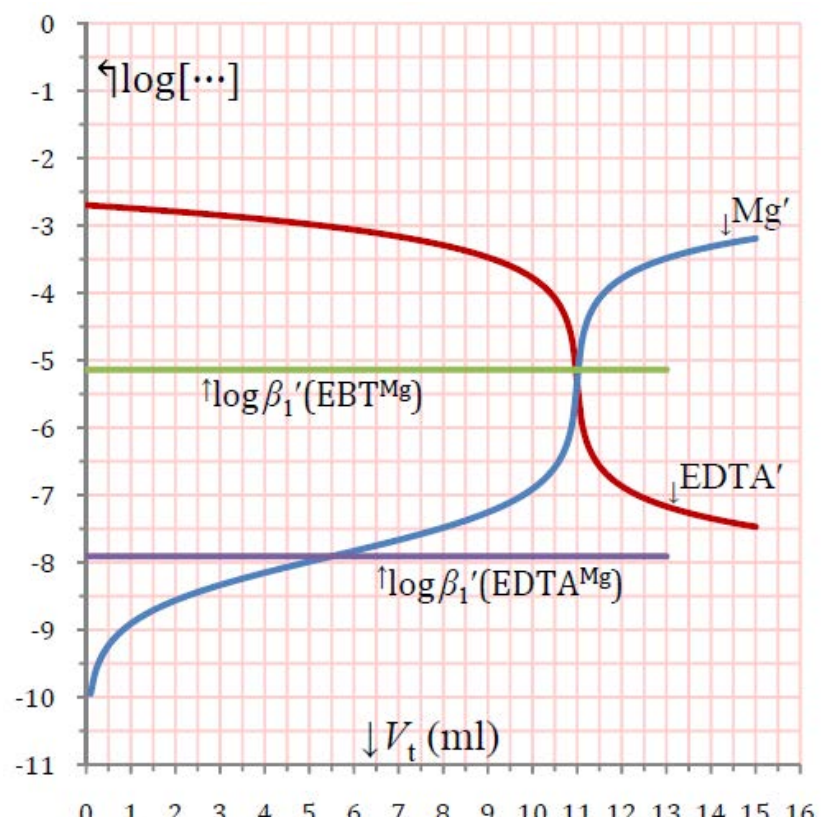

Figure 11. Graphical presentation of the titration of $110 \mathrm{ml}$ of $0.002 \mathrm{M}$ EDTA with standard $0.02 \mathrm{M} \mathrm{Mg}^{2+}$ in an ammoniacal solution $(0.91 \mathrm{M}$ $\mathrm{NH}_{3}+0.012 \mathrm{M} \mathrm{NH}_{4} \mathrm{Cl} ; \mathrm{pH} \approx 10.2$ ) in presence of Eriochrome Black T as indicator. Reference horizontal lines of ordinate $-\log \beta_{1}{ }^{\prime}\left(\mathrm{EBT}^{\mathrm{Mg}}\right)=-5.14$ and $-\log \beta_{1}{ }^{\prime}\left(\right.$ EDTA $\left.^{\mathrm{Mg}}\right)=-7.91$ are also shown

As a matter of fact Figure 11 is generated with $<$ ArrayGenerator $>$ simply by entering the concentration of the magnesium standard solution in place of that of the EDTA standard solution and vice versa. Then, data are transferred, as usually, to $<$ MyTitrationMatrix $>$ sheet and labels for EDTA' and Mg' are exchanged.

By observing Figure 11, it is clear that Eriochrome Black $T$, which is a suitable indicator for the direct titration, is not appropriate for the back-titration.

In fact, obviously, during the back-titration, the change of colour is reversed and the titration is stopped when the initial blue colour turns to red.

This will happen when $\log \left[\mathrm{Mg}^{\prime}\right] \approx-\log \left(\beta_{1}{ }^{\prime}\left(\mathrm{EBT}^{\mathrm{Mg}}\right)\right)+1$ $=-4.14$ and then much after the equivalence point (producing an enormous error in excess on the amount or concentration of EDTA).

Then, once again, we should change Eriochrome Black $\mathrm{T}$ with an indicator of higher sensitivity.

However we can circumvent this problem in a very ingenious way, if a second burette containing the $0.02 \mathrm{M}$ EDTA standard solution used for direct titrations is at hand.

In this case, once we have, during the back-titration surpassed the equivalence point and the solution has 
become red, we continue briefly the titration with the EDTA standard solution until the red solution just reassumes the initial blue colour. At this point $\log [\mathrm{Mg}$ '] $\approx$ $\left(-\log \left(\beta_{1}{ }^{\prime}\left(\mathrm{EBT}^{\mathrm{Mg}}\right)\right)-1\right)=-6.14$, as in the direct titration, and we are reasonably close to the equivalence point.

Obviously, we still read on the burette with the magnesium standard solution a volume $V_{\text {arr }} \gg V_{\text {eq }}$. However, we can correct $V_{\text {arr }}$ and evaluate a corrected $V_{\mathrm{arr}}^{\text {corr }}$ volume (to employ in calculations in place of the erroneous $V_{\text {arr }}$ ) using relation (58) (which makes use of the concentrations, $C_{\mathrm{t} \rightarrow \mathrm{Mg}}^{\mathrm{M}}$ and $C_{\mathrm{t} \rightarrow \mathrm{EDTA}}^{\mathrm{M}}$ of the magnesium and EDTA titrating solutions, and of the volume of EDTA standard solution, $\Delta V_{\mathrm{EDTA}}$, necessary to re-establish the initial blue colour in the solution after it had become red because of the addition of the standard magnesium solution).

$$
V_{\mathrm{arr}}^{\text {corr }}=V_{\mathrm{arr}}-\frac{C_{\mathrm{t} \rightarrow \mathrm{EDTA}}^{\mathrm{M}}}{C_{\mathrm{t} \rightarrow \mathrm{Mg}}^{\mathrm{M}}} \Delta V_{\mathrm{EDTA}}
$$

Equation (58) is very simple in case $C_{\mathrm{t} \rightarrow \mathrm{EDTA}}^{\mathrm{M}}=C_{\mathrm{t} \rightarrow \mathrm{Mg}}^{\mathrm{M}}$, because the correct volume of the titrating standard magnesium solution is simply obtained by subtracting the small volume of EDTA standard solution just necessary to re-establish the initial blue colour.

In abstract, $V_{\text {arr }}^{\text {corr }}$ represents the volume of magnesium which would be measured if we were able to stop the back-titration of EDTA with magnesium in the same point we arrest the direct titration of magnesium with EDTA, i.e. when $\log \left[\mathrm{Mg}^{\prime}\right] \approx-\log \left(\beta_{1}{ }^{\prime}\left(\mathrm{EBT}^{\mathrm{Mg}}\right)\right)-1=-6.14$.

It is evident that the above described back-titration of EDTA with magnesium has the same absolute accuracy than the direct titration but opposite in sign, since actually it is stopped before the equivalence point at $\log \left[\mathrm{Mg}^{\prime}\right]_{\mathrm{eq}}=$ 5.32 .

Please note that, according to the above described procedure, back-titrations end with a solution in the titration flask which has the same colour as the initial solution (which is a rather unusual feature for a visual titration).

Finally, the determination of calcium in absence of magnesium can be performed using Eriochrome black T as indicator, but two burettes, filled respectively with a $C_{\mathrm{t} \rightarrow \text { EDTA }}^{\mathrm{M}}$ standard solution of EDTA and a $C_{\mathrm{t} \rightarrow \mathrm{Mg}}^{\mathrm{M}}$ standard solution of magnesium sulphate are needed.

First, to the calcium solution in a titration flask a slight excess of EDTA is added from the corresponding burette and, then, the ensuing solution is treated, as usual, with a few $\mathrm{ml}$ of the $\mathrm{pH}=10$ ammoniacal buffer. Finally, sufficient Eriochrome Black $\mathrm{T}$ indicator is added to develop a distinct blue colour. The blue solution is titrated with the magnesium sulphate standard solution until a red colour is developed. Finally, the initial blue colour is re- established with the standard EDTA solution. The number of moles of calcium can be calculated from the difference between the number of moles of EDTA and the number of moles of magnesium consumed in the titration (which, in turn, are calculated from the consumed volumes of the two standard solutions and from their concentrations).

Evidently, this procedure avoids the formation of the inert CaEDTA' complex, because the indicator is added after a controlled excess of EDTA (which effectively mask the calcium) has been added.

Obviously, it is an error to add the Eriochrome Black T powder before the addition of the EDTA excess.

As in the case of the replacement titrations, the determination of a variety of metals can be reduced, using the above procedure, to the back-titration of EDTA with a standard magnesium sulphate solution.

From the above discussion, the special significance of the titration of magnesium with EDTA and vice versa in the context of complexometric titrations with aminopolycarboxylic acid should be apparent.

\section{Conclusions}

The chemical origin of the complexity of complexometric titrations of metal cations with aminopolycarboxylic acids is fully displayed and it is districated by introducing a chemical model based on the notions of groups of chemical species and reactions between groups of chemical species. This should help undergraduates to get a better understanding of the old concept of conditional complex formation constant.

\section{References}

[1] Hart, J. R., Ethylenediaminetetraacetic Acid and Related Chelating Agents" in Ullmann's Encyclopedia of Industrial Chemistry, (c) Wiley-VCH, Weinheim, 2005.

[2] Hage, D. S., Carr, J. D., Analytical Chemistry and Quantitative Analysis, (C) Pearson Education Inc., Prentice Hall, N. J., 2011.

[3] Skoog, D.A., West, D. M., Holler, F. J., Fundamentals of Analytical Chemistry, 7th ed., Saunders College Publishing, Philadelphia 1996.

[4] Pribil, R., Applied Complexometry, Pergamon Series in Analytical Chemistry Volume 5, (C) Pergamon Press Ltd., Oxford, 1982.

[5] Ringbom, A., Complexation Reactions, Chapter 14 in Kolthoff, I.M., Elving, P.J. and Sandell, E.B. (eds), Treatise on analytical chemistry, (C) The Interscience Encyclopedia, Inc., New York, 1959.

[6] Wilson, C.M., Wilson, D.W., Comprehensive Analytical Chemistry, Vol. IB, (C) Elsevier Publishing Company Inc., New York, 1960.

[7] Smith, R.M., Martell, A.E., Critical stability Constants, Vol. 1-4, (C) Plenum Press, New York, 1976.

[8] Burgot J. L., Ionic Equilibria in Analytical Chemistry, (C) Springer Science+Businiss Media, New York, 2012.

[9] Salvatore, F., Introduzione all'Uso Analitico delle Reazioni di Formazione di Complessi, (C) CUES editrice s.r.l., Fisciano, Italy, 2011. 